\title{
Comparing those who do, might and will not invest in sustainable funds: a survey among German retail fund investors
}

\author{
Anett Wins ${ }^{1} \cdot$ Bernhard Zwergel $^{2}$
}

Received: 21 November 2014/ Accepted: 28 January 2016/Published online: 19 February 2016

(C) The Author(s) 2016. This article is published with open access at Springerlink.com

\begin{abstract}
In this paper, we present the results of an online questionnaire among private German mutual fund investors. In an exploratory nature, we empirically analyze the differences between three groups: sustainable investors, conventional investors that are either generally interested or those that are not interested at all to invest in socially responsible (SR) funds. We provide evidence on motives and attitudes of these three investor groups, showing that SR fund investors are quite similar to those interested in investing sustainably and very different from those who only consider investing conventionally. All three groups agree that sustainable actions of a company affect its stock price positively. Yet, they all believe that SR funds perform worse than conventional funds. Nevertheless, some still invest in SR funds. Consequently, different motives and attitudes are the determining factors when it comes to making an investment decision. These differences will be extensively discussed on the following pages.
\end{abstract}

Keywords Ethical investors · Sustainable investors · Pro-social attitudes · Socially responsible investment $\cdot$ SRI $\cdot$ Survey

JEL classification G11

Bernhard Zwergel

b.zwergel@uni-kassel.de

Anett Wins

anett.wins@wiwi.uni-augsburg.de

1 Chair of Statistics, University of Augsburg, Universitätsstr. 16, 86159 Augsburg, Germany

2 Chair of Corporate Finance, University of Kassel, Henschelstr. 4, 34109 Kassel, Germany 


\section{Introduction}

During the last two decades the area of socially responsible investments (SRI) has grown substantially. Between 1995 and 2012 SRI assets in the US rose more than $480 \%$ to $\$ 3.74$ trillion in 2012 (Forum for Sustainable and Responsible Investment (2013)). The German market grew about $9 \%$ with respect to 2012 values. In 2013 it is estimated to have a value of $€ 79.9$ billion (FNG (2014)). One possibility for private investors to participate in the SRI market is to invest in socially responsible (SR) funds. According to the FNG (2014), €12.7 billion are invested in roughly 300 SR retail funds that are available in Germany. Currently, this corresponds to $1.8 \%$ of the total volume of the German mutual retail fund market. Therefore, it has great potential to grow strongly in the following years, especially when Germany is compared to The Netherlands, the European frontrunner, where SR retail funds amount almost to a total of $15.4 \%$ of the volume of the Dutch mutual retail fund market (see Vigeo Rating (2013)). SR funds in Germany mostly practice negative screening and/or follow a best in class investment approach (see FNG (2014)). When the performance of SR and conventional retail funds domiciled in Germany are compared, no significant underperformance of SR funds can be found (Cortez et al. 2009, 2012; Renneboog et al. 2008; Kreander et al. 2005; Bauer et al. 2005; Schröder 2004; Kreander et al. 2002)). Globally, there are more than 100 studies concerning the performance of SR funds (e.g., Chegut et al. 2011; Rathner 2013; von Wallis and Klein 2014). Capelle-Blancard and Monjon (2012) point out that "maybe too much attention has been paid to this issue". Therefore, we want to add to the "few studies [which] examine the aspirations of SRI investors".

Whereas the supply side for sustainable funds is quite visible (vgl. http://www. nachhaltiges-investment.org/) and the products are known, very little information is attainable regarding the demand side. We try to shed light on the people investing in SR funds, so-called sustainable, green, socially conscious or simply SR fund investors. In the following, we primarily use the latter term since it seems to be the one most commonly used these days. SR fund investors' preferences go beyond only considering risk and return when making an investment decision as it is expected for a rational investor (see Statman (2005)). They additionally include non-financial measures like social, ethical, or environmental (SEE) criteria in their considerations when thinking about investing in a corporation. In other words, a company should be profitable and should conform to a certain minimum corporate social responsibility (CSR) standard; otherwise, it is an unsuitable investment for an SR fund investor. Yet, as Kitzmueller and Shimshack (2012) state "CSR is not necessarily incompatible with profit maximization".

To date, the survey-based evidence on investors who invest in SR funds is geographically highly segmented, and the research questions are fairly diverse. Most studies solely consider SR investors and some studies compare SR with conventional investors. An overview regarding the surveys of the last three decades can be found in Wins and Zwergel (2015).

Besides our survey only Dorfleitner and Utz (2014) take a look at German SR investors. They concentrate on German investors in general whom they first segment 
into three subgroups, namely private investors, asset managers, and institutional investors. There is no strict author-defined differentiation between SR and conventional investors. Nonetheless, their survey gives a very good impression on the general motives for investing in SR funds. However, since they had to keep the questions very general in order to be able to pose meaningful questions for participants from investors to asset managers, they did not have the possibility to directly employ questions and constructs that are common in the SR investor survey literature.

The key contributions of this paper are threefold:

With our exploratory research, we empirically analyze the differences between three investor groups, thereby explicitly considering the heterogeneity of conventional investors regarding their general attitude towards investments in SR funds: sustainable fund investors (SR), conventional investors that are either generally interested (INT) or those that are not interested at all (CONV) to invest in SR funds. Thereby we provide evidence on the motives and attitudes of these three investor groups especially concerning pro-social influences. Using the classification tree (CT) method we show that SR fund investors are quite similar to those interested in investing sustainably und very different from those who only consider investing conventionally. Furthermore, we can show that four variables suffice to segment the three investor groups with an accuracy rate of $65.6 \%$. When SR and INT are merged, representing the group of investors being generally reachable for SR investing (REACH), the segmentation accuracy rate can even be increased to about $75 \%$. Employing ordinal logistic regression analysis (OLR), we determine influential factors on the percentage of SR funds in an investor's fund portfolio.

Secondly, we describe the fund investors' views regarding the influence of sustainability in general and regarding its elements (social, ethical, and ecological issues) on the performance of companies.

Thirdly, we examine the question of how SR funds ought to be designed, e.g., which investment strategies they ought to employ, to appeal to German SR fund investors.

The remainder of the paper is organized as follows. In the next section, we develop hypotheses with respect to the existing literature for SR, INT, and CONV investors, followed by the description of our study design and the demographic profile of the three investor groups (Sect. 3). In Sect. 4, we further survey investor type characteristics and thereby investigate the previously claimed hypotheses. Two different multivariate methods of analysis (OLR, CT method) are applied in Sect. 5 to fathom influential factors for SR investing behavior as well as an indication for essential investor group differences and reasons of INT investors for not investing in SR funds. A conclusion is drawn in Sect. 6.

\section{Literature review and hypothesis development}

\subsection{Demographics}

Previous research (e.g., Rosen et al. (1991), Tippet and Leung (2001), Schueth (2003), McLachlan and Gardner (2004), Nilsson (2008), Junkus and Berry (2010), 
Cheah et al. (2011), Pérez-Gladish et al. (2012)) concerning the comparison of the demographic profiles of ethical and conventional investors led a priori to some common beliefs concerning different socio-demographic characteristics like gender, age, educational background, income level, or the place of residence. This is quite surprising since study results are rather diverse and sometimes even contradictory: often due to problems of representativeness as well as temporal and/or geographical differences of the respective data. Since our sample is not representative, we refrain from explicit comparisons with other survey results. Nonetheless, we will test the following hypothesis fitted to our three investor groups (SR, INT, and CONV investors) concerning the connection between demographics and investment behavior.

Several studies (e.g., Rosen et al. (1991), Tippet and Leung (2001), Junkus and Berry (2010), Cheah et al. (2011)) have already shown that due to SRI being a recent movement ethical investors tend to be younger and predominantly female as "women (...) [bring] a natural affinity to the concept of socially responsible investing with them" (Schueth (2003)).

H1a The proportion of female investors rises with the respondents' involvement to SR investing (from CONV to INT to SR fund investors).

H1b SR fund investors will be younger than their inactive (INT) or conventional (CONV) counterparts.

"[T]he better-informed investors are, the more responsible their actions tend to be" (Schueth (2003)). Therefore, it seems to be reasonable to assume a positive link between the respondents' educational degree and their involvement to SR investing (see also Rosen et al. (1991), Nilsson (2008), Tippet and Leung (2001), Cheah et al. (2011)).

H1c The proportion of better educated (university graduate) investors rises with the respondents' involvement to SR investing (from CONV to INT to SR fund investors).

Concerning the income and wealth level of ethical compared to conventional investors, contradictory views are advanced in the literature. Whereas Junkus and Berry (2010), Tippet and Leung (2001), and Rosen et al. (1991) characterize SR investors to be "less affluent" or/and having "lower median household (...) incomes", McLachlan and Gardner (2004), Nilsson (2008), as well as Cheah et al. (2011) assume that better earning and/or wealthier investors "may be more willing to tolerate "ethical penalty'". Following this reasonable assumption, we suppose:

H1d The proportion of investors with a higher income level rises with the respondents' involvement to SR investing (from CONV to INT to SR fund investors).

Some researchers (e.g., Nilsson (2008), Pérez-Gladish et al. (2012)) a priori propose SEE issues and therefore SR investing to be predominantly relevant for larger cities' inhabitants, whereas rural areas are less affected. Hence, we adopt: 
H1e The proportion of investors living in urban areas rises with the respondents' involvement to SR investing (from CONV to INT to SR fund investors).

Beyond that, Diamantopoulos et al. (2003) state that two out of the three studies analyzing environmental behavior find that married people show more green behavior than those who are single. Additionally, Brooker (1976) and Grunert (1993) find a positive relationship between environmental behavior and the number of children. Junkus and Berry (2010) conclude that the SR investors are more likely to be single than their conventional counterpart, whereas Pérez-Gladish et al. (2012) find no effect between the marital status and the level of SR fund investment. Since results regarding the marital status and parenthood of SR investors are inconclusive, we follow the findings from the environmental behavior literature and assume SR fund investors to be more frequently and stronger involved in social and family structures. Therefore, we suppose:

H1f SR fund investors will be more likely to be (quasi) married and parents than their interested (INT) or conventional (CONV) counterparts.

Furthermore, we expect SR fund investors to be more dedicated to voluntary activities as an additional expression of their pro-social behavior. This assumption will be reconsidered in detail under hypothesis $\mathrm{H} 2 \mathrm{~b}$.

\subsection{Social, ethical, and environmental (SEE) factors (pro-social influence)}

Many studies discuss SR investors' possible motives (e.g., Anand and Cowton (1993), Beal and Goyen (1998), Beal et al. (2005), Haigh (2008), and Jansson and Biel (2011)). However, very few papers focus on them and empirically go beyond what we describe in the section on investment strategies (e.g., negative screening criteria). Especially, the question why the topic sustainability is important for them remains unanswered. We apply three scales developed by Nilsson (2008) to fathom the motives that drive SR investors when they assign capital to ethical funds: prosocial attitudes (PSA), trust and perceived consumer effectiveness (PCE).

PSA, social identity (see Bauer and Smeets (2015)) and pro-social consumer behavior are interlinked. However, many studies report that this connection is not as strong as one might think. Instead, there seems to be an "attitude-behavior gap" (Boulstridge and Carrigan (2000)). ${ }^{1}$ Vyvyan et al. (2007) conduct an investment preference experiment and reveal that all investors, including individuals who rate environmental concerns highly, rank performance-related criteria the highest. This provides further support for an attitude-behavior gap. Nonetheless, Nilsson (2008) shows that PSA regarding the issues addressed by SR funds significantly impact consumer behavior in a positive manner (questions see "Appendix: Pro-social Influence").

H2a: PSA regarding the issues addressed in SRI will affect consumer behavior for SR funds in a positive way.

\footnotetext{
${ }^{1}$ For a further discussion on the links between pro-social attitudes, pro-social consumer behavior, perceived consumer effectiveness, and trust in SRI, see Nilsson (2008).
} 
Following this train of thought, it is also plausible to assume that people, who engage in voluntary activities, thus not only stating PSA but also acting in a prosocial fashion, will be more likely to invest in SR funds.

H2b Voluntary activities will affect consumer behavior for SR funds in a positive way.

In the pro-social consumer behavior domain, consumer skepticism and confusion about environmental and social claims have become a serious problem (e.g., Crane (2000)). Additionally, green claims used in advertising are not seen as credible and trustworthy, often resulting in the rejection of green products. Accordingly an investor who trusts in pro-social claims made by SR funds should be more likely to invest in SR funds than someone who does not believe in the claims made by SR funds. However, Nilsson (2008) can neither support a positive nor a negative impact of trust in pro-social claims made by SR funds on consumer behavior.

H2c Trust in pro-social claims made in SRI will affect consumer behavior for SR funds in a positive way.

Among others Straughan and Roberts (1999) state that perceived consumer effectiveness (PCE) refers to the assumption that consumers are more likely to act according to environmental appeals if they have confidence that their behavior will help to solve the issue at hand. They show that PCE is the strongest predictor of ecologically conscious consumer behavior. Nilsson (2008) adopts this concept for individuals investing in SR funds. His findings show a significant positive impact of PCE with regard to investing in SR funds.

H2d PCE with regard to SRI will affect consumer behavior for SR funds in a positive way.

\subsection{Sustainability defined and its influence on return}

In many studies (e.g., Pérez-Gladish et al. (2012), Sandberg and Nilsson (2011), McLachlan and Gardner (2004), Anand and Cowton (1993)) respondents were asked regarding the investment strategies that a fund should employ. Almost every study deals with negative screening criteria somehow or other. We will discuss this topic in a later section because we are of the opinion that one should first try to define the term sustainability before investment strategies are discussed. According to the European SRI study from 2012, published by Eurosif (the European Sustainable Investment Forum) "no consensus on a unified definition of SRI exists within Europe". Instead the term SRI strongly depends on the cultural and historical background of each country. Therefore, we present the definition of FNG (Forum Nachhaltige Geldanlagen) $)^{2}$ : "Sustainable investments supplement the traditional criteria of profitability, liquidity and security with environmental, social and ethical evaluation criteria." But how do investors define sustainability and hence

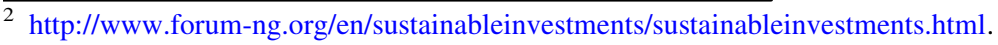


sustainable investments and how important is the topic sustainability for them in general?

Since, the three investor groups (SR, INT and CONV), according to our definition, differ in their degree of interest in SR funds and their actual investment behavior, it is plausible to expect the following:

H3a SR, INT and CONV investors will hold different views on the constituting elements of sustainability.

We assume that the definition of sustainable investments given by the FNG is the consensus that has been reached by its members. Therefore, it could be representative for German SR investors. Accordingly, we assume:

H3b SR fund investors will hold a holistic view on sustainability.

As Rosen et al. (1991) already note, ethical investors do not regard ethical investments as a charitable donation. Accordingly, SR fund investors might expect a positive link between sustainability and financial performance. Since INT and CONV investors do not invest in SR funds, we expect them to be of the opinion that sustainability negatively affects stock returns. Subsequently, we assume:

H3c SR fund investors assume that a positive link between sustainable actions of companies and their financial performance exists.

H3d INT and CONV investors assume that a negative link between sustainable actions of companies and their financial performance exists.

\subsection{Financial perceptions of SR funds (profit orientated influence)}

Although many studies concerning the performance of equity SR funds have already been conducted and several reviews (e.g., Chegut et al. (2011), Rathner (2013), von Wallis and Klein (2014)) have been written, no significant under- or outperformance compared to conventional investments has been proven. But often the subjective assessment fairly differs from the objective one. Nevertheless, the subjective perception of financial return and risk are the central decision-making factors in any investment decision (Nilsson (2008)). As the primary aim of investing money is to receive financial return, these subjective perceptions are expected to raise the probability of holding any SR funds independent of the attitude toward the consideration of SEE issues if the investor is of the opinion that SR funds perform better than conventional funds. This leads to the following hypotheses:

H4a SR, INT and CONV investors' return perception of ethical funds compared to conventional funds differ with CONV investors assuming the most negative return difference. 
H4b SR, INT and CONV investors' risk perception of ethical funds compared to conventional funds differ with CONV investors assuming the most negative risk difference. $^{3}$

Further hypotheses concerning investors' expectations toward financial and nonfinancial issues can be devised following particularly McLachlan and Gardner (2004) and Pérez-Gladish et al. (2012). SR fund investors pursue wealth creation, as the general aim of investments just like a conventional investor. However, SR fund investors additionally impose the constraint to conform to certain ethical standards, occasionally also described as some kind of 'ethical penalty' (Cheah et al. (2011)). Therefore, we expect:

H4c SR fund investors will be less profit orientated than INT and CONV investors.

According to portfolio theory, an increased risk due to reduced diversification in SR portfolios can be assumed (Pérez-Gladish et al. (2012)). Subsequently, it can be anticipated that:

H4d SR fund investors will be less risk averse than INT and CONV investors.

Beyond that, according to McLachlan and Gardner (2004), ethical investors will rate ethical issues as more important to their investment decision than conventional investors. Nevertheless, several studies (e.g., Rosen et al. (1991), Sandberg and Nilsson (2011), Dorfleitner and Utz (2014)) indicate that most SR investors are not willing to sacrifice a considerable amount of financial return. Bringing together both aspects, we assume:

H4e SR fund investors are concerned about financial as well as non-financial characteristics of their investments.

\subsection{Investment strategies}

Since the survey of Rosen et al. (1991), where respondents were asked to list factors that "are most important in determining whether a company's behavior can be considered socially responsible", most studies have focused on exclusion as the major investment strategy of SR investors, because Rosen et al. (1991) report that an "overwhelming majority of responses ( 83 percent) relate to avoidance activities: 'bad' things the firm should not do". McLachlan and Gardner (2004) are among the first to explicitly include engagement, confrontation and inclusion as possible investment strategies in their survey among conventional and ethical Australian investors. This seems to be very reasonable, since the latter is closely linked to the 'best-in-class' investment approach which has become very popular among fund managers. This approach is very similar to the conventional way of constructing a portfolio where stocks are included given that they meet preset criteria regarding return and risk. In Michelson et al. (2004), best-in-

\footnotetext{
${ }^{3}$ Since we did not give a definition for the term 'risk', it might be possible that the three investor groups differ regarding its definition. A SR fund investor, who might have a key concern for, e.g. the environment, could have a broader interpretation of the term 'risk' than a conventional investor. This is a limitation of our study and an interesting subject for further research. We are grateful to an anonymous referee for pointing this out to us.
} 
class is described as a means of selecting companies for an SR fund that belong to an apparently 'bad' industry, but who are the most responsible in their trade.

Sparkes and Cowton (2004) states that when engagement is practiced "socially responsibility concerns will be implemented not directly in the composition of the portfolio but by using shareholder ownership rights to influence corporate behavior, seeking to steer it in a more socially responsible direction". McLachlan and Gardner (2004) describe confrontation as an investment strategy that seeks to publicly embarrass a company.

According to the above descriptions, exclusion, engagement and confrontation appear to be more closely linked to socially responsible than to conventional investing:

H5a There will be a greater proportion of SR and INT investors than CONV investors choosing exclusion, engagement, or confrontation as their preferred investment strategy, whereas for inclusion the reverse is expected.

Since exclusion seems to be the strategy with the longest tradition among SR investors, we follow Rosen et al. (1991), Anand and Cowton (1993), McLachlan and Gardner (2004) and Dorfleitner and Utz (2014) through confronting our respondents with topics related to ecological, social, and moral dimensions. These issues are often mentioned in the academic literature and in SR fund prospectuses where they are used as negative screening criteria (e.g., child labor (social), animal experiments (moral), extraction of raw materials (ecological)). Therefore, they seem to be important SRI issues. We expect that SR fund investors' concern about sustainability will be mirrored by strong views regarding the importance of the presented issues.

H5b SR and INT investors will rate sustainable issues as more important to their investment decisions than CONV investors.

\section{Survey design and data collection}

\subsection{Sampling procedure}

To gather information about private German mutual fund investors, their attitudes toward SRI, their beliefs, morals and motives, and their investment behavior, as well as to investigate differences between different investor groups (SR, INT, and CONV investors), we created an extensive online survey for the German-speaking market, originally in German. We excluded other forms of SR investments from the survey since that would have been beyond the scope of our study, which is to shed light on the people investing in SR funds. ${ }^{4}$ Further information regarding German SR investors in general

\footnotetext{
${ }^{4}$ Additionally, we think that the number of people who directly invest in sustainable stocks is much smaller than those who invest in SR funds, because it is more time-consuming to acquire the necessary information regarding sustainability for stocks and closed-end funds than for open-end retail equity funds. Besides, according to Deutsche Bundesbank (2013) $17 \%$ of German households own funds, whereas only $11 \%$ hold stocks and in 2012 only $0.8 \%$ of German investors owned closed-end funds (see Statista.com).
} 
can be found in Dorfleitner and Utz (2014) and a broader perspective on SR investments in general and their impact on corporate change can be found in Haigh and Hazelton (2004).

The survey period lasted from January 19, 2012 to July 15, 2012. ${ }^{5}$ To reach a link to the relevant research issues in the existing literature, questions from different papers (e.g., Lewis and Mackenzie (2000a), McLachlan and Gardner (2004), Nilsson (2008), and Sandberg and Nilsson (2011)) were brought together and supplemented. Following McLachlan and Gardner (2004), we did not present the study as being about sustainability, to keep participants from shifting their answers in a more socially desirable direction. Thus minimizing the potential impact of social desirability bias (Chung and Monroe (2003)). The questionnaire was published on and distributed via several German investment fund-related (sustainable and conventional) fora, websites, and foundations, as well as among other researchers. Hence, we reached a sample independent of any one fund provider or association. The respondents identified themselves as ethical fund investors ('I have already invested money in sustainable funds'), being interested in SR funds ('I never have invested money in sustainable funds, but I am interested in'), or conventional fund investors ('I have not invested money in sustainable funds, nor am I interested in investing in sustainable funds'). Prior to the above 'grouping' question the following definition was given: "In the following sustainable funds (as opposed to conventional funds) are funds that not only adhere to financial criteria (e.g., return and risk) but also consider ecological (e.g., environmental protection), social (e.g., child labor) or ethical (e.g., arms exports) criteria." After sorting out unusable replies (e.g., no target group member, inconsistent answers, unfeasible duration time, etc.) and those without the above 'grouping' question, the dataset ${ }^{6}$ comprises 421 respondents: 72 of them being current (60) or former (12) SR fund investors, 155 being interested in SR funds, and 194 being conventional investors. Due to the extensiveness or partial complexity of the questionnaire, not all participants answered all questions. Therefore, the dataset comprises certain missing values. Wherever necessary or reasonable, the relevant number of respondents is given by $N$.

\subsection{Participants' demographics}

All relevant results are displayed in Table 1. There are two coexistent SR fund investor definitions in the literature: current SR fund investors (which we abbreviate in tables with 'SR'); current and former SR fund investors. We include descriptive statistics as well as results of the Chi-squared test on the equality of distributions and Goodman-Kruskal gammas (rank correlations) for both SR fund investor definitions in Table 1. Whereas the Chi-squared test is reported to show whether there are distribution differences between the three investor types (SR, INT, CONV)

\footnotetext{
${ }^{5}$ We would like to thank Florian Kobell for maintaining the online survey and all survey participants for answering the questionnaire.

${ }^{6}$ The complete dataset and its description is available for free: https://www.wiwi.uni-augsburg.de/ bwl/okhrin/team_okhrin/anett_wins/.
} 


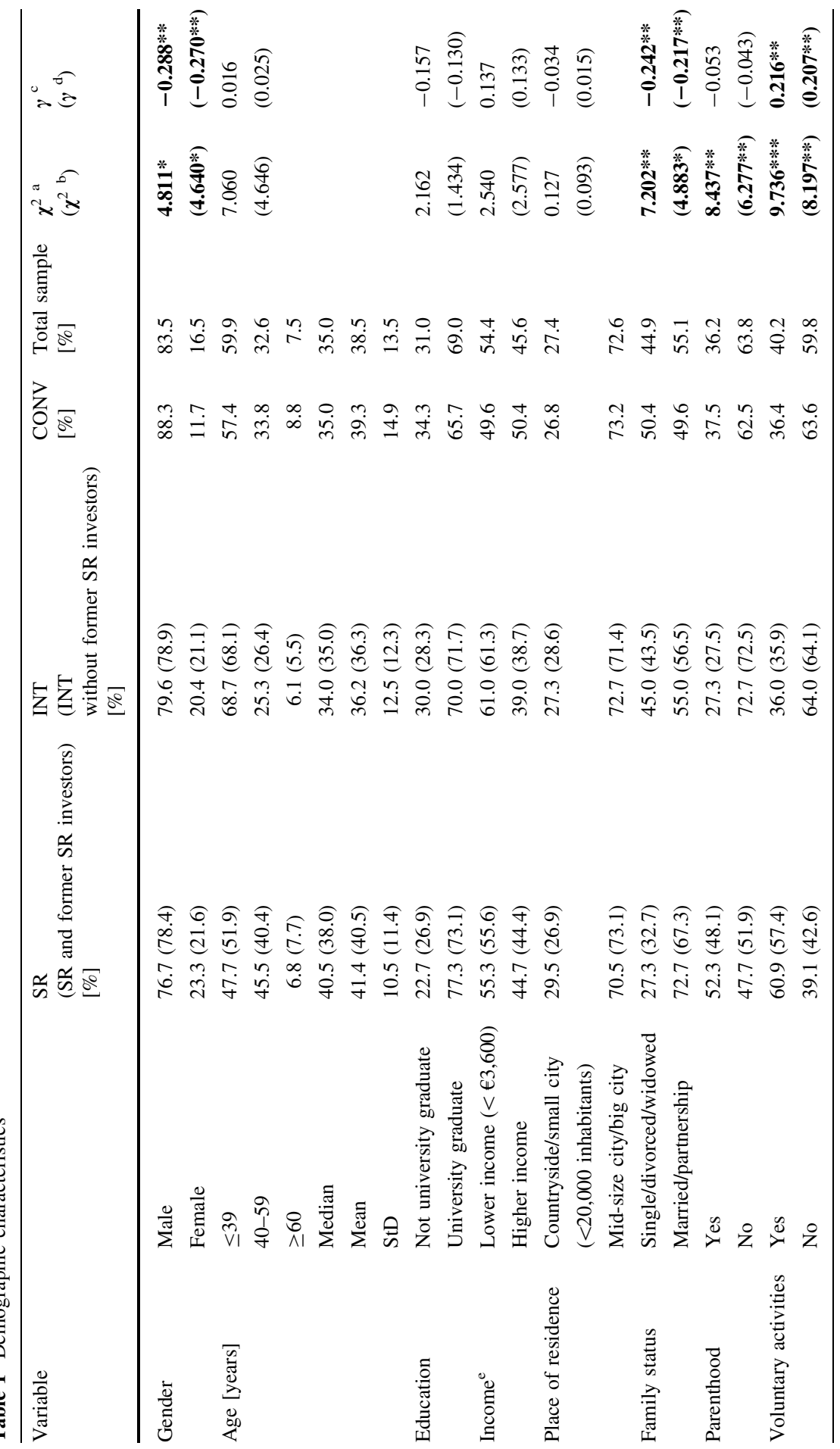




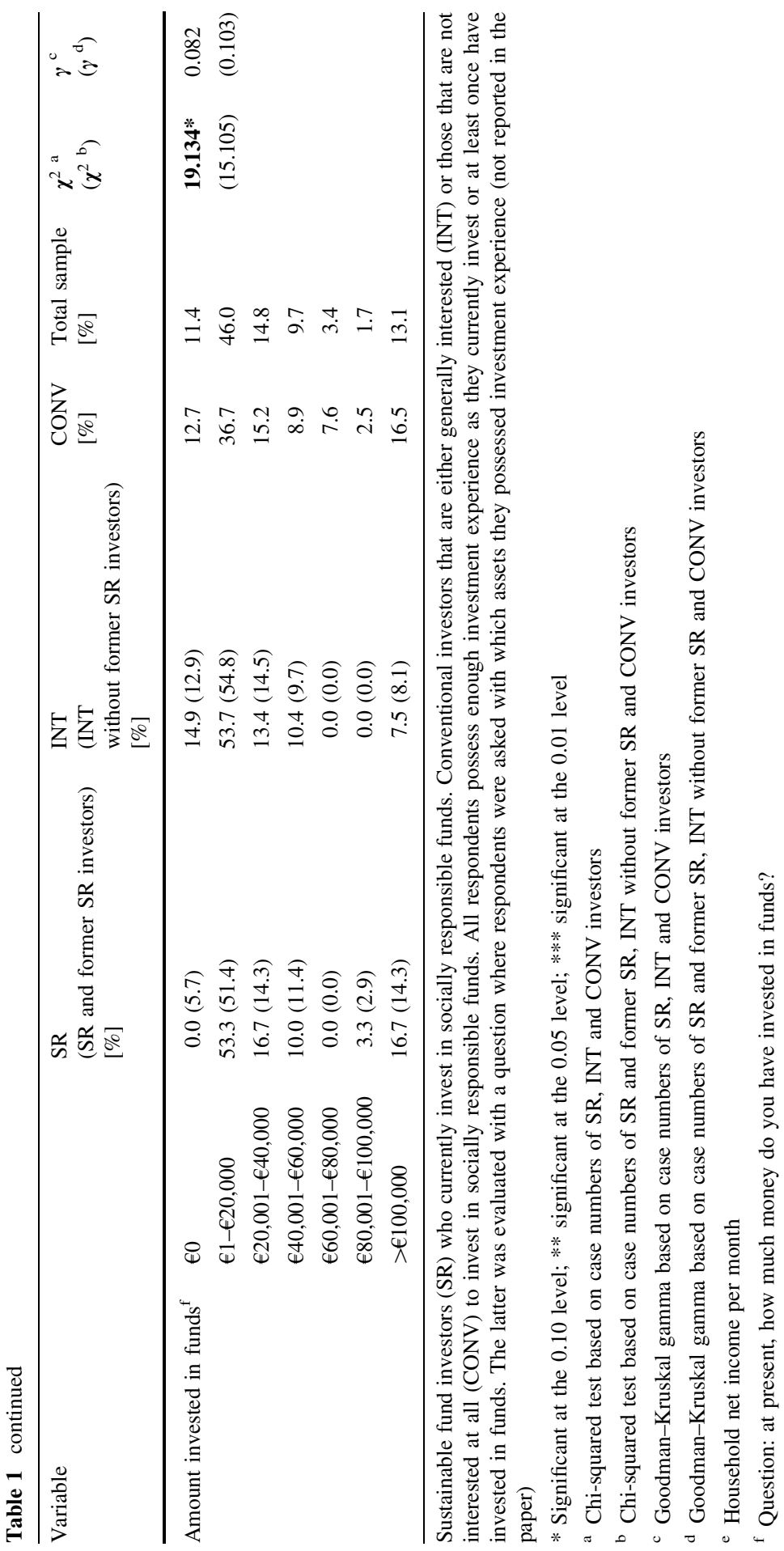


at all, the Goodman-Kruskal gamma (rank correlation) is used to measure the monotonous association for ordinal scaled attributes-one being the involvement to SR investing that rises from CONV across INT to SR. Therefore, GoodmanKruskal gamma is relevant to decide on hypothesis H1a to H1f. Due to the small number of 12 former SR fund investors in the sample, no relevant differences in the descriptive statistics, in the test significances or the rank correlations were observable for both investor type definitions referred to in Table 1.

Our whole sample is predominantly male $(83.5 \%)$, young to middle aged and throughout well educated (69.0\% university graduates). The gender distribution of our sample overestimates the percentage of male investors: according to Deutsches Aktien Institut (DAI (2014b)) only $63 \%$ of German fund investors are male. Furthermore, in comparison to the age structure declared by DAI (2014a) our sample is younger. Both aberrations introduce a bias. They might be due to our online sampling procedure. Therefore, generalizations from our sample have to be treated with care.

Most participants live in mid-sized or big cities $(72.6 \%)$ and four out of nine respondents have an available monthly household net income above $€ 3,600$. A majority is (quasi) married $(55.1 \%)$ and (still) childless $(63.8 \%)$. Furthermore, with about $57 \%$ holding a total investment amount of less than $€ 20,000$, the majority of our sample seems to be not very wealthy.

At least marginally significant differences in the distributions of SR, INT, ${ }^{7}$ and CONV investors were discovered for the gender ratio as well as the variables family status, parenthood, voluntary activities, and the total investment amount in funds. Nevertheless, an interpretable relationship due to the significance of GoodmanKruskal gamma can only be stated for the gender relation and the variables family status and voluntary activities: the proportion of female investors rises significantly with the personal involvement to SR issues (from CONV to INT to SR fund investors), thus supporting hypothesis H1a. The same (tendency) can be constituted for (quasi) married investors as well as the proportion of volunteers. Significant differences in the status of parenthood and the total investment amount for the three investor types are observable, but there is no clear tendency subject to the level of SR involvement: SR fund investors are about 1.9 (1.4) times more often parents than INT (CONV) investors. All together, these results support hypothesis H1f.

However, no significant differences between the three investor types were found for the educational degree, the income level, the place of residence, and the age distribution. Hence, no support for hypotheses H1b to H1e is given.

\section{Investor type characteristics}

\subsection{Social, ethical, and environmental (SEE) factors (pro-social influence)}

According to Nilsson (2008) pro-social attitudes (PSA) towards the SEE issues addressed by SR funds, trust in SR funds and the perceived consumer effectiveness (PCE) regarding the ability of SR funds to solve the issues addressed in SRI

\footnotetext{
7 The group INT already includes the former SR fund investors.
} 
Table 2 Pro-social attitudes (PSA), perceived consumer effectiveness (PCE), trust in SR funds and their connections to the percentage of capital invested in SR funds

\begin{tabular}{|c|c|c|c|c|c|c|c|c|}
\hline & & CONV & $\begin{array}{l}\text { INT without } \\
\text { former SR } \\
\text { investors }\end{array}$ & $\begin{array}{l}0 \% \\
\text { in } \mathrm{SR} \\
\text { funds }^{\mathrm{b}}\end{array}$ & $\begin{array}{l}1-20 \% \\
\text { in SR } \\
\text { funds }\end{array}$ & $\begin{array}{l}21-80 \% \\
\text { in SR } \\
\text { funds }^{b}\end{array}$ & $\begin{array}{l}81-100 \% \\
\text { in SR } \\
\text { funds }\end{array}$ & $\begin{array}{l}\text { Cronbach's } \\
\text { Alpha }\end{array}$ \\
\hline $\mathrm{PSA}^{\mathrm{a}}$ & $\begin{array}{l}\text { Mean } \\
\text { StD }\end{array}$ & $\begin{array}{c}2.71 \\
(1.05)\end{array}$ & $\begin{array}{c}3.71 \\
(0.80)\end{array}$ & $\begin{array}{c}3.33 \\
(1.37)\end{array}$ & $\begin{array}{c}3.61 \\
(1.21)\end{array}$ & $\begin{array}{c}4.34 \\
(0.75)\end{array}$ & $\begin{array}{c}4.26 \\
(0.96)\end{array}$ & 0.894 \\
\hline $\mathrm{PCE}^{\mathrm{a}}$ & $\begin{array}{l}\text { Mean } \\
\text { StD }\end{array}$ & $\begin{array}{c}2.88 \\
(0.84)\end{array}$ & $\begin{array}{c}3.98 \\
(0.76)\end{array}$ & $\begin{array}{c}3.44 \\
(1.21)\end{array}$ & $\begin{array}{c}4.16 \\
(0.76)\end{array}$ & $\begin{array}{c}4.23 \\
(0.67)\end{array}$ & $\begin{array}{c}4.68 \\
(0.47)\end{array}$ & 0.785 \\
\hline Trust $^{\mathrm{a}}$ & $\begin{array}{l}\text { Mean } \\
\text { StD }\end{array}$ & $\begin{array}{c}2.57 \\
(0.94)\end{array}$ & $\begin{array}{c}3.20 \\
(0.70)\end{array}$ & $\begin{array}{c}3.07 \\
(1.03)\end{array}$ & $\begin{array}{c}3.41 \\
(0.81)\end{array}$ & $\begin{array}{c}3.87 \\
(0.64)\end{array}$ & $\begin{array}{c}3.54 \\
(0.82)\end{array}$ & 0.807 \\
\hline \multicolumn{2}{|c|}{$\begin{array}{c}\% \text { of total } \\
\text { sample }\end{array}$} & 49.2 & 31.9 & 3.1 & 7.8 & 4.7 & 3.4 & \\
\hline \multicolumn{2}{|c|}{$\begin{array}{l}\% \text { of SR } \\
\text { investors }\end{array}$} & & & 16.1 & 41.1 & 25.0 & 17.9 & \\
\hline
\end{tabular}

Sustainable fund investors (SR) that currently invest in socially responsible funds. Conventional investors that are either generally interested (INT) or those that are not interested at all (CONV) to invest in socially responsible funds

a The attitudinal scales pro-social attitudes (PSA), perceived consumer effectiveness (PCE) and trust in SR funds are each mean values based upon four to five questions measured on a 5-point Likert scale ( $1=$ 'not at all important' $\ldots 5=$ 'very important'). For further background information on the scale values PSA, PCE and trust see Appendix

b Columns 5-8 show the averaged values of the three constructs (PSA, PCE, trust) for former SR fund investors who currently have no money invested in SR funds ('0 \% in SR funds') and current SR fund investors across different investment levels (1-20\%, 21-80\%, 81-100\%)

describe the pro-social influences on socially responsible investment behavior. Since each of the three constructs is composed of several questions (see "Appendix") that relate to social, environmental, and ethical factors, we think that PSA, PCE, and trust go beyond the aspect of social influence: They additionally incorporate possible morals and motives of investors. Table 2 displays the results of the three constructs for our sample.

It is obvious that conventional investors do not only have the lowest average values of the three investor groups, but also that their values are the only ones below 3.0 (on a 5-point Likert scale anchored by 'not at all important' (1) and 'very important' (5)). The group with the second lowest average values are the INT investors (without former SR fund investors, since they are displayed in column '0 \% in SR funds' in Table 2). The current and former SR fund investors, combined across all investment levels, show the highest average values (PSA: 3.86, PCE: 4.15, trust: 3.49). Hence, this is a clear indication supporting hypothesis $\mathrm{H} 2 \mathrm{a}, \mathrm{H} 2 \mathrm{c}$ and $\mathrm{H} 2 \mathrm{~d}$, that PSA, PCE, and trust impact consumer behavior for socially responsible investments in a positive fashion. ${ }^{8}$

\footnotetext{
${ }^{8}$ We performed one-sided (alternative hypothesis: "greater") $t$-tests for each attitudinal scale value, making pairwise comparisons between the three investor groups. All the test results were highly significant $(\alpha=1 \%)$ except for the comparison of SR vs. INT regarding PSA which was only marginally significant $(\alpha=10 \%)$.
} 
When looking at the results for the different levels of investment in SR funds among the current and former SR fund investors, two effects are evident. First, values for all three constructs tend to increase with the percentage of capital invested in SR funds. However, it is worth noting that the values of those SR fund investors that once had SR funds but currently have not allocated any money to SR funds (0 \% in SR funds) are always below the INT (without former SR) investors' values but above the CONV investors' values. Second, standard deviations (StD) tend to decrease with the percentage of capital invested in SR funds. Again, former SR fund investors ( $0 \%$ in SR funds) hold a prominent position. The standard deviations of this group are highest among all investor groups. This circumstance brought us to take a closer look at its constituents and their individual PSA, PCE and trust values. Roughly, half of the former SR fund investors have values for the three constructs that are closer to those of the typical CONV investor and the rest has values that are more similar to those of the typical current SR fund investor. Yet, more than half of the individuals of the former SR fund investor group have only two values of the three constructs that correspond either to the typical current SR fund investor or the typical CONV investor. For example, there is an individual with PSA 4.40, PCE 3.75 but trust 2.00. The first two values are similar to those of typical current SR fund investors, whereas the third value more likely corresponds to typical CONV investors.

Due to the fact that they no longer actively invest in ethical funds, we decided to regroup the former SR fund investors: as these respondents were once interested enough to invest in SR funds and their exit from the funds does not necessarily mean their interest for SR investments completely disappeared, we included the former SR fund investors in the INT group. From Sect. 4.2 on, we therefore report results for the three groups: current SR fund investors (SR), interested investors and former SR fund investors (INT) as well as conventional investors (CONV). Nonetheless, as a robustness check (not reported), we computed the values for all tables regarding the SR group consisting of current and former SR fund investors leaving most results quantitatively unchanged as can be exemplarily seen in Table 1. Even completely dropping former SR fund investors from the sample did not lead to changes worth mentioning (not reported). Treating former SR fund investors as a separated group is no reasonable option due to the small number of 12 respondents of whom solely nine completed the questionnaire.

As mentioned earlier pro-social attitudes and pro-social consumer behavior (i.e., buying SR funds) are interlinked. However, many studies report that this connection is not as strong as one might think. Instead, there seems to be an "attitude-behavior gap" (Boulstridge and Carrigan (2000)). This gap becomes obvious when we look at the PSA value of a typical INT investor (without former SR fund investors): this value is higher than the average value of SR fund investors, who invest 1-20\% of their capital in SR funds. Additional support for the existence of this attitudebehavior gap is given by another fact: SR fund investors more often engage in voluntary activities than INT and CONV investors (see Table 1) thus supporting $\mathrm{H} 2 \mathrm{~b}$. This supports the notion, that ethical investing is particularly done by people, who show some pro-social behavior. Yet, this leaves one question unanswered: What must happen to an INT investor to become an SR fund investor? Although we 
give some possible answers to this question in Sect. 5.2, they remain superficial and therefore this question is an interesting topic for further research.

\subsection{Sustainability defined and its influence on return}

When the respondents of our survey were asked to state the importance of the topic sustainability for them, SR and INT investors perceived it to be important averaging 4.04 and 3.87 on a 5-point Likert scale anchored by 'not at all important' (1) and 'very important' (5). Unsurprisingly, the average of CONV investors is much lower at 2.75. However, without knowing what these groups subsume under the term 'sustainability' the above averages are difficult to interpret. Therefore, we asked our respondents which issue comes first to mind when thinking about the term sustainability. Table 3 shows how the different expressions (ecological, social, ethical, and economic issues) are connected to it. At first glance it is evident, that the three investor groups have different views on the subject of sustainability. This impression is confirmed by the result of a Chi-squared test $(\alpha=1 \%)$ on the equality of the distribution of the votes for the constituting elements of sustainability, thus supporting hypothesis H3a. Whereas $86.2 \%$ of SR fund investors are of the opinion that sustainability comprises ecological, social, ethical, and economic issues, only $66.7 \%$ of the INT investors and $42.1 \%$ of the CONV investors share this view. Thus most SR fund investors share the holistic view for SRI given by FNG's definition (see Sect. 2.3). This finding supports H3b, that SR fund investors have the most holistic view on sustainability $(\alpha=1 \%)$. Many respondents of the two other groups have more narrow views on sustainability: $16.4 \%$ and $18.4 \%$ of INT and CONV investors, respectively, think that ecological issues are the most dominant element of sustainability. Economic issues are believed to be the most prevalent topic by $9.1 \%$ of INT investors and almost one-fifth of CONV investors.

Subsequent to the different 'sustainability' comprehensions, it makes sense to look at the investor groups' assessments of how ecological, social, ethical, or sustainable actions affect the stock price of a company, in the long run. The respondents ratings are based on a 5-point Likert scale anchored by $1=$ 'negative' and $5=$ 'positive'. Especially in the empirical sciences "it has become common

Table 3 Sustainability defined

\begin{tabular}{lrrr}
\hline $\begin{array}{l}\text { Which issue comes first to mind when thinking about the term Sustainability? } \\
\text { (select one alternative) }\end{array}$ & $\begin{array}{l}\text { SR } \\
{[\%]}\end{array}$ & $\begin{array}{l}\text { INT } \\
{[\%]}\end{array}$ & $\begin{array}{l}\text { CONV } \\
{[\%]}\end{array}$ \\
\hline Ecological issues & 3.4 & 16.4 & 18.4 \\
Social issues & 1.7 & 3.0 & 1.1 \\
Ethical issues & 0.0 & 3.6 & 3.2 \\
Economic issues & 6.9 & 9.1 & 19.5 \\
All of the above & 86.2 & 66.7 & 42.1 \\
None of the above & 1.7 & 1.2 & 15.8 \\
\hline
\end{tabular}

Sustainable fund investors (SR) that currently invest in socially responsible funds. Conventional investors that are either generally interested (INT) or those that are not interested at all (CONV) to invest in socially responsible funds 
practice to assume that Likert-type categories constitute interval-level rather than ordinal-level measurement" (Blaikie (2003)) and therefore to report mean values and t-test ${ }^{9}$ results for the comparison of two independent samples. Knowing that this might be discussable and produce impreciseness due to the originally rather ordinal data measure, we additionally report the medians as well as the ranges and besides used the Wilcoxon test. This non-parametric alternative test-approach avoids the use of mean values which cannot adequately describe the location of a non-continuous distribution. The test results are generally quite robust: there are differences in significances only on rare occasions. Therefore, we primarily discuss mean values and t-test results and additionally allude to relevant divergences between the parametric and non-parametric tests.

Table 4 shows, that all three groups are on average of the opinion that ethical, social, as well as ecological actions (at least slightly) positively affect a company's stock price, whereat ecological actions are expected to have a more positive influence than the other two. The combination of the three previously mentioned actions, sustainable actions, is expected to have the most positive influence on a company's stock price. Accordingly, all three investor groups seem to be of the opinion that the whole (sustainability) is more than the sum of its parts. These results support hypothesis $\mathrm{H} 3 \mathrm{c}$, which states that $\mathrm{SR}$ fund investors assume a positive link between sustainable actions of companies and their financial performance $(\alpha=1 \%)$. However, hypothesis $\mathrm{H} 3 \mathrm{~d}$, which states that INT and CONV investors assume a negative link between sustainable actions of companies and their financial performance, cannot be supported, since their averages are higher than three. This raises the question why INT and CONV investors do not invest in sustainable funds, since they represent a portfolio of stocks that undertake sustainable actions? In the following section, we will present potential explanations why this might be the case.

\subsection{Financial perceptions of SR funds (profit orientated influence)}

From Table 5 it becomes obvious that the respondents' return perception differ $(\alpha=1 \%)$ among the three investor types: Whereas the SR fund investors predominantly perceive sustainable funds' performance to be not considerably worse or even almost equal to conventional funds' performance, a majority of $66.3 \%$ of the INT investors and even $68.9 \%$ of the CONV investors expect at least slightly or even much lower financial returns of sustainable funds compared to conventional funds. This underestimation of SR funds' performance is not in line with empirical findings regarding the performance of SR funds domiciled in Germany. Cortez et al. (2012), Cortez et al. (2009), Renneboog et al. (2008), Kreander et al. (2005), Bauer et al. (2005), Schröder (2004) and Kreander et al. (2002) detect no significant underperformance of SR funds domiciled in Germany compared to conventional funds.

\footnotetext{
9 Norman (2010) reports "that many studies (...) consistently show that parametric statistics are robust with respect to violations of the (...) assumption of [(a) adequate sample size, (b) normally distribution and (c) not ordinal (Likert-scaled) data]."
} 


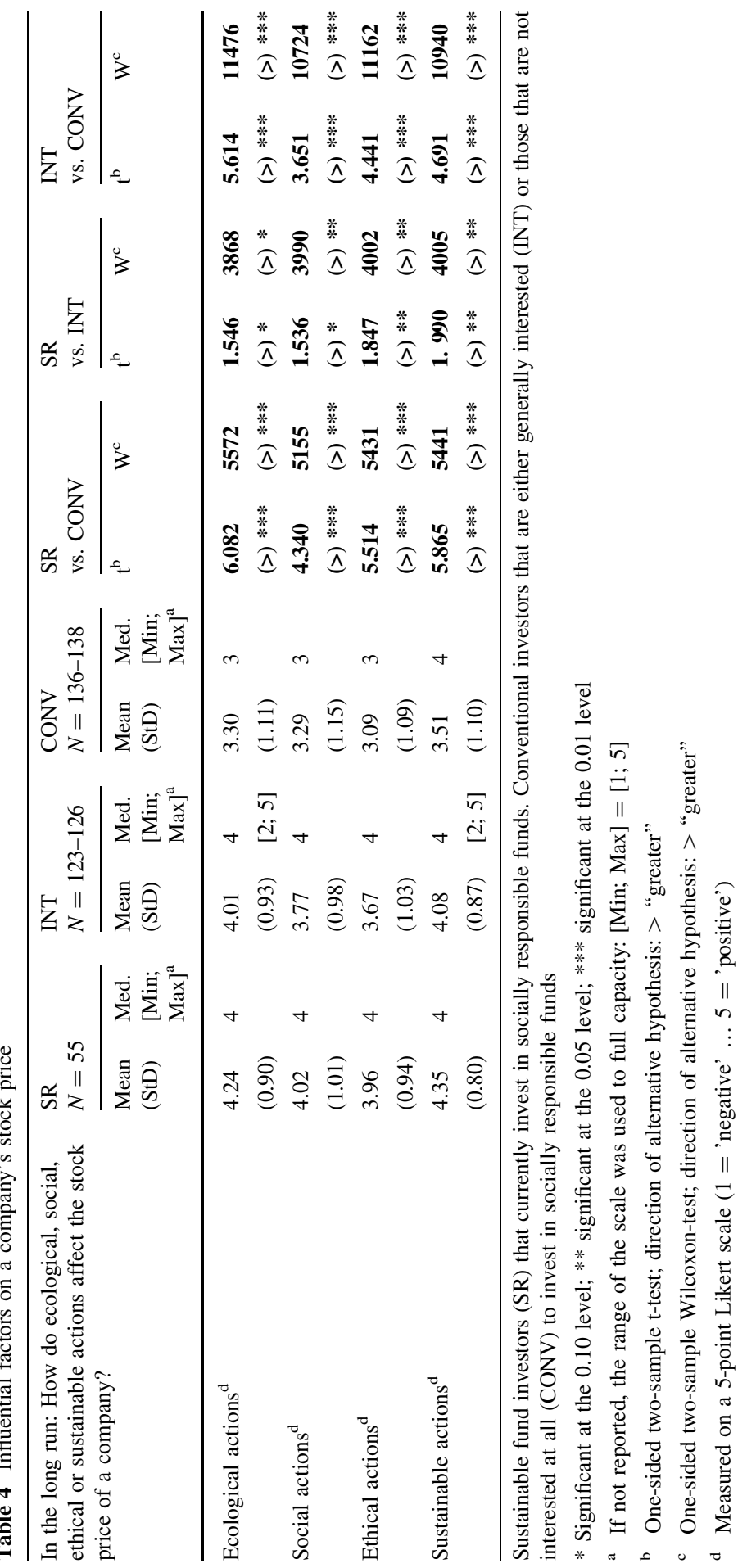


Table 5 Perception of return

\begin{tabular}{llll}
\hline $\begin{array}{l}\text { Financial return of sustainable funds } \\
\text { compared to conventional funds }\end{array}$ & $\begin{array}{l}\text { SR } \\
{[\%]}\end{array}$ & $\begin{array}{l}\text { INT } \\
{[\%]}\end{array}$ & $\begin{array}{l}\text { CONV } \\
{[\%]}\end{array}$ \\
\hline Much lower (1) & $N=51$ & $N=116$ & $N=122$ \\
Slightly lower (2) & 7.8 & 12.9 & 28.7 \\
Similar rate of financial return (3) & 39.2 & 53.4 & 40.2 \\
Slightly higher (4) & 39.2 & 25.9 & 29.5 \\
Much higher (5) & 11.8 & 5.2 & 1.6 \\
Mean & 2.0 & 2.6 & 0.0 \\
StD & 2.61 & 2.31 & 2.04 \\
\hline
\end{tabular}

Sustainable fund investors (SR) that currently invest in socially responsible funds. Conventional investors that are either generally interested (INT) or those that are not interested at all (CONV) to invest in socially responsible funds

Chi-squared test on respondents' return perception among the three investor types: $\chi^{2}=27.427, d f=8$, $\boldsymbol{p}=0.001$

Table 6 Perception of risk

\begin{tabular}{lccc}
\hline $\begin{array}{l}\text { Risk of sustainable funds compared } \\
\text { to conventional funds }\end{array}$ & $\begin{array}{l}\text { SR } \\
{[\%]}\end{array}$ & $\begin{array}{l}\text { INT } \\
{[\%]}\end{array}$ & $\begin{array}{l}\text { CONV } \\
{[\%]}\end{array}$ \\
& $N=52$ & $N=119$ & $N=126$ \\
\hline Much riskier (1) & 1.9 & 5.9 & 9.5 \\
A little riskier (2) & 21.2 & 29.4 & 24.6 \\
About the same (3) & 51.9 & 41.2 & 54.0 \\
A little less risky (4) & 23.1 & 18.5 & 11.1 \\
A lot less risky (5) & 1.9 & 5.0 & 0.8 \\
Mean & 3.02 & 2.87 & 2.69 \\
StD & 0.78 & 0.95 & 0.82
\end{tabular}

Sustainable fund investors (SR) that currently invest in socially responsible funds. Conventional investors that are either generally interested (INT) or those that are not interested at all (CONV) to invest in socially responsible funds

Chi-squared test on respondents' risk perception among the three investor types: $\chi^{2}=14.856, d f=8$, $\boldsymbol{p}=0.062$

However, the three investor groups' risk perceptions do not differ significantly with most respondents expecting sustainable funds to be as risky as or just slightly riskier than conventional funds. Nevertheless, the CONV investors' view is by trend again the most pessimistic one (see row with mean values in Table 6). This slight overestimation of risk is not in line with empirical findings: Bauer et al. (2005) and Kreander et al. (2005) conclude that ethical funds in Europe and Germany tend to be less market sensitive and thus less risky than their conventional counterparts. This is also supported by Kempf and Osthoff (2008) who state that "SRI funds [in the US] have a smaller market sensitivity than the conventional funds. Hence, hypothesis H4a could statistically be confirmed, whereas there is no support for hypothesis H4b. 
Table 7 Willingness to change the portfolio composition in different performance scenarios

\begin{tabular}{|c|c|c|c|c|c|c|c|c|}
\hline \multirow{3}{*}{$\begin{array}{l}\text { 5-year average } \\
\text { annual return of } \\
\text { sustainable or } \\
\text { ordinary fund }\end{array}$} & & \multicolumn{6}{|c|}{ Answering options } & \multirow{3}{*}{$\begin{array}{l}\text { Chi-squared test } \\
\chi^{2}\end{array}$} \\
\hline & & \multicolumn{2}{|c|}{$\begin{array}{l}\text { Reduce my } \\
\text { sustainable } \\
\text { investments }\end{array}$} & \multicolumn{2}{|c|}{$\begin{array}{l}\text { Leave things as } \\
\text { they are }\end{array}$} & \multicolumn{2}{|c|}{$\begin{array}{l}\text { Increase my } \\
\text { sustainable } \\
\text { investments }\end{array}$} & \\
\hline & & $\begin{array}{l}\mathrm{SR} \\
{[\%]}\end{array}$ & $\begin{array}{l}\text { INT } \\
{[\%]}\end{array}$ & $\begin{array}{l}\mathrm{SR} \\
{[\%]}\end{array}$ & $\begin{array}{l}\text { INT } \\
{[\%]}\end{array}$ & $\begin{array}{l}\mathrm{SR} \\
{[\%]}\end{array}$ & $\begin{array}{l}\text { INT } \\
{[\%]}\end{array}$ & \\
\hline Sustainable & $5 \%$ & 38.6 & 64.9 & 47.7 & 20.7 & 13.6 & 14.4 & $11.884 * * *$ \\
\hline Ordinary & $10 \%$ & & & & & & & \\
\hline Sustainable & $8 \%$ & 6.8 & 27.0 & 65.9 & 48.6 & 27.3 & 24.3 & $7.906 * *$ \\
\hline Ordinary & $10 \%$ & & & & & & & \\
\hline Sustainable & $12 \%$ & 2.3 & 6.3 & 27.3 & 17.9 & 70.5 & 75.9 & 2.465 \\
\hline Ordinary & $10 \%$ & & & & & & & \\
\hline
\end{tabular}

Sustainable fund investors (SR) that currently invest in socially responsible funds. Conventional investors that are generally interested (INT) to invest in socially responsible funds. Respondents were asked the following question: Imagine that over the next five years the best sustainable fund produced an ... percent average financial return, whereas a typical ordinary fund produced a ... percent average annual return. Assume everything else remains the same. Question: Which of the following would you do? (Select one alternative: Reduce my sustainable investments; Leave things as they are; Increase my sustainable investments)

* Significant at the 0.10 level; ** significant at the 0.05 level; *** significant at the 0.01 level

For further investigations concerning financial perceptions of SR funds and the influence on the respondents' virtual investment behavior, we confronted the SR and INT investors with three different scenarios: two with sustainable funds' under- and one with sustainable funds' outperforming conventional funds. The aim was to research the degree of the investors' willingness to sacrifice financial returns in favor of sustainable investment behavior or in general their affinity to change their portfolio composition of sustainable and conventional funds. Relevant results are displayed in Table 7. These have to be treated with care since they are to some extend influenced by artificiality (Bardsley (2005)) and framing (Glac (2009)).

SR and INT investors' fictitious investment behavior significantly differs for the two underperforming scenarios, with INT investors acting more return oriented. This impression is most pronounced in the $5 \%$ vs. $10 \%$ scenario, where almost $65 \%$ of INT compared to less than $40 \%$ of SR fund investors would reduce their sustainable investments slightly or even substantially. Remarkably, almost every second SR fund investor would not change his portfolio composition in this investment scenario with this inferior performance of SR funds. Instead, he accepts reduced financial returns in favor of his continued commitment to his sustainable investment. ${ }^{10}$ The results for German SR fund investors are quite in line with those

\footnotetext{
${ }^{10}$ Some investors even choose to increase the percentage of their SR fund investments when returns of SR funds are half that of conventional funds. We cannot be certain that these answers actually reflect investor behavior. Actually, we know that the majority of these investors believes that the returns of SR funds are lower than those of conventional funds. This at least does not make the answers implausible for a utility maximizing investor. Additionally, the above phenomenon also occurs in Webley et al. (2001) and less strongly in Lewis and Mackenzie (2000a).
} 
obtained by Webley et al. (2001) and Lewis and Mackenzie (2000a) in similar scenarios for SR investors from the UK. ${ }^{11}$ Altogether, this suggests that the INT investors hold a more profit-orientated view than SR fund investors, which is also supported by their self-assessment concerning the importance of high returns for investments in general (cp. Table 8). Corresponding to the appropriate one-sided two-sample t-test, high returns are on average significantly $(\alpha=5 \%)$ more important for INT than for SR fund investors. The same result is obtained for the comparison between $\mathrm{CONV}$ and SR fund investors $(\alpha=5 \%)$, whereas the hypothesis of equal importance of high returns by INT and CONV investors cannot be rejected. Hence, hypothesis $\mathrm{H} 4 \mathrm{c}$ is statistically confirmed.

Analogically, no significant differences in the self-assessments concerning the average importance of low risk for investments in general (cp. Table 8) were obtained between SR, INT and CONV investors. Therefore, hypothesis H4d, suggesting SR fund investors to be less risk averse than INT or CONV investors, could not be confirmed. We can rather conclude that low risk is on average equally important for the three investor groups.

In order to investigate differences of the considered aspects in the investment process by the three investor groups, the respondents were asked to rate various financial and non-financial issues (cp. Table 8) on a 5-point Likert scale anchored by 'not important at all' (1) and 'very important' (5). Significant differences $(\alpha=1 \%)$ were observable for SR, INT and CONV investors concerning the average rating of the importance of considering social, ethical, and environmental (SEE) criteria, resulting in a significantly higher rating of SR than INT $(\alpha=1 \%)$ and INT than CONV investors $(\alpha=1 \%)$. But how do the different investor groups assess the importance of different financial aspects (apart from a low expected risk $^{12}$ ) compared to the group-specific importance of the non-financial criterion of SEE considerations? Therefore, we compared for each investor type the groupspecific mean value of the issue 'consideration of SEE criteria' (e.g., SR: 3.56) with the group-specific mean values of the financial criteria 'high return' (e.g., SR: 3.86), 'low asset-based fees' (e.g., SR: 3.80), 'low total expense ratio' (e.g., SR: 3.79), 'low performance fee' (e.g., SR: 3.57), and 'low transaction costs' (e.g., SR: 3.79), resulting in five mean value comparisons ( $\mathrm{t}$-tests) per investor group. No significant difference between the average rating of financial criteria and the non-financial criterion of SEE considerations were observable for the SR fund investors, whereas CONV and INT investors ascribe on average significantly $(\alpha=1 \%)$ more importance to all of the financial issues than to considerations of SEE criteria. These results support hypothesis $\mathrm{H} 4 \mathrm{e}$, suggesting SR fund investors to be simultaneously concerned about financial and non-financial characteristics, whereas CONV as well as INT investors are primarily concerned about financial issues.

\footnotetext{
11 A clear aberration occurs in the scenario where ethical funds have higher returns than ordinary funds. Maybe it is due to artificiality that some SR and INT investors would reduce their investment in ethical funds. This effect is less strong in Lewis and Mackenzie (2000a) and nonexistent in Webley et al. (2001).

12 This issue has been excluded from the following comparisons due to its obviously different impact than return, cost, or fee-based topics.
} 


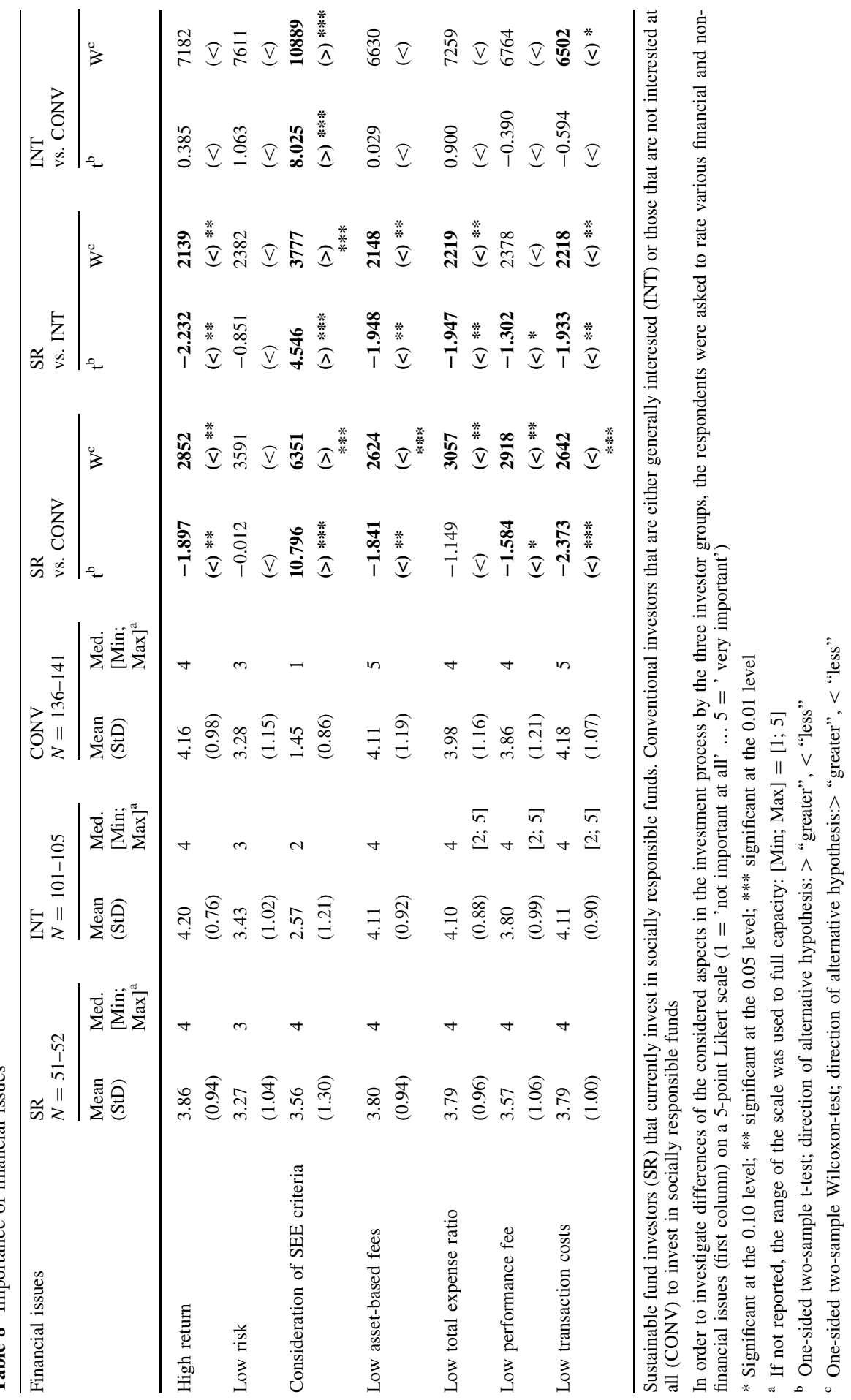




\subsection{Investment strategies}

In this section, we take a detailed look at the investors' considerations when investing money. Furthermore, we describe the opinions of SR and INT investors regarding the strategies used by sustainable equity funds.

Roughly one-third of German SR (28.8\%) and INT (38.7\%) investors and more than two-thirds of CONV (69.5\%) investors neither prefer inclusion, exclusion, engagement, nor confrontation as their primary investment strategy.

However, most investors of all three groups prefer an investment strategy that primarily focuses on actively including stocks in their portfolio, in other words they select investments that are in line with their values or investment targets. This approach corresponds to the positive screening done by SR funds. Exclusion is preferred by fewer SR fund investors $(25.0 \%)$ and it is only favored by $13.2 \%$ of INT and $2.8 \%$ of CONV investors (Table 9). As in McLachlan and Gardner (2004), almost no one chose confrontation as their key investment strategy. Furthermore, when the percentages are adjusted, omitting our last response option ("none of the above strategies') more CONV (67.4\%) than SR fund $(51.4 \%)$ investors chose inclusion as their preferred investment strategy and more SR $(35.1 \%)$ than CONV $(9.3 \%)$ investors chose exclusion as their number one strategy. A Chi-squared test on the equality of the distributions of the three groups confirms $(\alpha=1 \%)$ that preferred investment strategies between the three investor groups differ. Yet, hypothesis $\mathrm{H} 5 \mathrm{a}$, that there will be a greater proportion of SR fund investors than CONV investors in all investment stages with the exception of inclusion, cannot be supported.

The above result that inclusion is the preferred strategy connects well with our findings and that of Sandberg and Nilsson (2011) where ethical investors are asked whether SR funds should avoid investing in companies perceived by investors to be ethically problematic (cp. Table 10). Approximately $94 \%$ of the Swedish ethical investors, $79.6 \%$ of the German SR and $88 \%$ of the INT investors are of the opinion that SR funds should not invest in companies, which can be considered as ethically problematic. Accordingly, only a small fraction $(20.4 \%$ of SR and $12 \%$ of INT investors) is attracted to best in class funds. Hence, SR and INT investors

Table 9 Primary investment strategies

\begin{tabular}{lrrr}
\hline $\begin{array}{l}\text { Please tick only one of the investment strategies (used by funds) that } \\
\text { you prefer. }\end{array}$ & $\begin{array}{l}\text { SR } \\
{[\%]}\end{array}$ & $\begin{array}{l}\text { INT } \\
{[\%]}\end{array}$ & $\begin{array}{l}\text { CONV } \\
{[\%]}\end{array}$ \\
& $N=52$ & $N=106$ & $N=141$ \\
\hline Exclusion & 25.0 & 13.2 & 2.8 \\
Inclusion & 36.5 & 31.1 & 20.6 \\
Engagement & 9.6 & 17.0 & 5.7 \\
Confrontation & 0.0 & 0.0 & 1.4 \\
None of the above strategies & 28.8 & 38.7 & 69.5 \\
\hline
\end{tabular}

Sustainable fund investors (SR) that currently invest in socially responsible funds. Conventional investors that are either generally interested (INT) or those that are not interested at all (CONV) to invest in socially responsible funds 
Table 10 Avoidance of ethically problematical companies

\begin{tabular}{lcc}
\hline $\begin{array}{l}\text { Do you think that ethical funds should avoid investing in companies that you } \\
\text { perceive to be ethically problematic? } \\
\text { (several options possible) }\end{array}$ & $\begin{array}{l}\text { SR } \\
{[\%]}\end{array}$ & $\begin{array}{c}\text { INT } \\
{[\%]}\end{array}$ \\
\hline No, they should not avoid investment in any businesses/industries & $N=108$ \\
Yes, they should avoid companies that pollute the environment & 20.4 & 12.0 \\
Yes, they should avoid companies that use child labor & 63.3 & 74.1 \\
Yes, they should avoid companies that produce tobacco, alcohol, or firearms & 67.3 & 79.6 \\
Yes: other alternative & 8.2 & 50.0 \\
(open question) & 1.9 \\
\hline
\end{tabular}

Sustainable fund investors (SR) that currently invest in socially responsible funds. Conventional investors that are generally interested (INT) to invest in socially responsible funds

rather seem to "gain their utility indirectly from the outcomes of the investment activities they support" (Cullis et al. (1992)). Thus, according to Cullis et al. (1992), they can be called investment-investors.

This result from Table 10 in combination with the findings from Table 9 that SR and INT investors primarily prefer an inclusionary strategy can be interpreted as the two sides of the same coin: an investor who for certain reasons actively includes investments in his portfolio automatically avoids those investments that do not match his investment criteria. This impression is further strengthened when we discuss the perceived effectiveness of engagement strategies (Table 12).

Can SR and INT investors act according to the above preferences? SR (retail and institutional) funds ${ }^{13}$ that are licensed for distribution in Germany account for $€ 30.9$ billion. €25.27 billion $(\sim 82 \%)$ of these assets practice negative screening and $€ 15.81$ billion $(\sim 51 \%)$ follow a best in class investment approach (see FNG (2014)). Thus, at most $18 \%$ of assets can be managed according to best in class without considering negative screens. This is roughly in line with the fraction of $20.4 \%$ of SR and $12 \%$ of INT investors who could be attracted to 'pure' best in class funds according to Table 10 . Consequently, more than $30 \%$ of the assets must be managed with a combination of the two strategies. Whether or not the SR funds match the preferences of SR and INT investors is impossible to clarify since the above data does not reveal which negative screens are employed and combined with the best in class approach. As mentioned in Dorfleitner and Utz (2014), it may also be possible that there is a gap between supply and demand for SR funds in Germanspeaking countries.

Results on where the line ought to be drawn whether a stock is ethical or not is shown in Table 11. $44.4 \%$ of SR and $42.6 \%$ INT respondents share the view that an SR fund should never invest in companies considered to be ethically problematic, while $40.0 \%$ of SR and $41.7 \%$ of INT investors state that it varies from case to case to what extent an SR fund should avoid investing in ethically problematic companies (Table 11).

$\overline{13}$ Unfortunately, no numbers for retail funds exclusively are available. 
Table 11 Extension of avoidance of ethically problematical companies

\begin{tabular}{lcc}
\hline $\begin{array}{l}\text { To what extent ought an ethical fund to avoid investing in ethically problematic } \\
\text { companies? } \\
\text { (select one alternative) }\end{array}$ & $\begin{array}{l}\text { SR } \\
{[\%]}\end{array}$ & $\begin{array}{l}\text { INT } \\
{[\%]}\end{array}$ \\
\hline $\begin{array}{l}\text { An ethical fund should never invest in any of these companies } \\
N=108\end{array}$ & 44.4 & 42.6 \\
$\begin{array}{l}\text { It may be acceptable to invest in companies that get less than 5\% of their } \\
\text { turnover from these products/practices, but no more }\end{array}$ & 13.3 & 12.0 \\
$\begin{array}{l}\text { It may be acceptable to invest in companies that get less than 10 \% of their } \\
\text { turnover from these products/practices, but no more }\end{array}$ & 2.2 \\
$\begin{array}{l}\text { It varies from case to case to what extent an ethical fund should avoid investing in } \\
\text { these companies }\end{array}$ & 40.0 & 41.7
\end{tabular}

Sustainable fund investors (SR) that currently invest in socially responsible funds. Conventional investors that are generally interested (INT) to invest in socially responsible funds

The findings above go well together with the answers in Table 12: German SR and INT investors are of the view that the most effective strategy an ethical fund could use to influence companies into becoming more socially responsible is to invest directly in companies with an ethical or environmental profile. To avoid investing in companies that fail to comply with certain ethical criteria ranks second for both investor groups.

Connecting the results from Tables 9 and 12, two things can be shown that again relate to the impression that exclusion (avoidance) and inclusion (investing ethically) are 'two sides of the same coin' from a private investor's point of view. First INT and SR fund investors who prefer exclusion as their primary investment strategy are of the opinion that investing ethically is the most effective strategy. ${ }^{14}$ Second INT and SR fund investors who prefer inclusion as their primary investment strategy are of the opinion that avoidance is at least one of the most effective strategies. ${ }^{15}$ Hence, it can be reasoned that the two subgroups above only use two different starting points (exclusion and inclusion) to achieve the same goal: a socially responsible portfolio. ${ }^{16}$

\footnotetext{
${ }^{14}$ For SR fund investors who prefer exclusion as their primary investment strategy, all the onesided (alternative hypothesis: "greater") paired t-tests, testing the most effective strategy (here in accordance to the mean value and median: investing ethically) against all the other strategies of Table 12 are significant $(\alpha=5 \%)$. For INT investors who prefer exclusion as their primary investment strategy four out of six one-sided paired t-tests are significant. The corresponding nonparametric Wilcoxon-tests completely support the t-test results. Detailed tables are available from the authors upon request.

15 The support for the second conclusion is less strong. For SR fund investors preferring inclusion as their primary investment strategy, only four (two) of the six one-sided paired t-tests (Wilcoxontests) are significant $(\alpha=5 \%)$. For the corresponding INT group this is the case for two of the six one-sided paired t-tests (Wilcoxon-tests).

${ }^{16}$ The remaining subgroups resulting from Table 9 (engagement and none) are not further analyzed since the SR and INT subgroups for the primary investment strategy 'none' did not show a most effective strategy and the subgroup of SR fund investors who prefer engagement as their primary investment strategy only consists of at most five investors and is thus too small for meaningful tests.
} 
Table 12 Perceived effectiveness of engagement strategies

\begin{tabular}{|c|c|c|c|c|c|c|}
\hline \multirow{2}{*}{$\begin{array}{l}\text { Below are a number of strategies which an } \\
\text { ethical fund could use to influence companies } \\
\text { into becoming more socially responsible. How } \\
\text { effective do you think that these strategies are? }\end{array}$} & \multicolumn{2}{|c|}{$\begin{array}{l}\mathrm{SR} \\
N=40-43\end{array}$} & \multicolumn{2}{|c|}{$\begin{array}{l}\text { INT } \\
N=85-95\end{array}$} & \multicolumn{2}{|l|}{$\begin{array}{l}\text { SR } \\
\text { vs. INT }\end{array}$} \\
\hline & Mean & $\begin{array}{l}\text { Med. } \\
{[\text { Min; }} \\
\text { Max }]^{\mathrm{a}}\end{array}$ & Mean & $\begin{array}{l}\text { Med. } \\
{[\text { Min; }} \\
{\text { Max }]^{\mathrm{a}}}^{\text {Mat }}\end{array}$ & $\mathrm{t}^{\mathrm{b}}$ & $\mathrm{W}^{\mathrm{c}}$ \\
\hline $\begin{array}{l}\text { To avoid investing in companies which fail to } \\
\text { comply with certain ethical criteria }\end{array}$ & $\begin{array}{l}3.93 \\
(1.14)\end{array}$ & 4 & $\begin{array}{l}3.97 \\
(1.19)\end{array}$ & 4 & $\begin{array}{l}-0.180 \\
(\neq)\end{array}$ & $\begin{array}{l}1985 \\
(\neq)\end{array}$ \\
\hline $\begin{array}{l}\text { To vote at the annual general meetings of } \\
\text { "unethical" companies }\end{array}$ & $\begin{array}{l}3.70 \\
(1.29)\end{array}$ & 4 & $\begin{array}{l}3.62 \\
(1.13)\end{array}$ & 4 & $\begin{array}{l}-0.325 \\
(\neq)\end{array}$ & $\begin{array}{l}1982 \\
(\neq)\end{array}$ \\
\hline $\begin{array}{l}\text { To conduct an active dialogue with "unethical" } \\
\text { companies }\end{array}$ & $\begin{array}{l}3.79 \\
(1.01)\end{array}$ & 4 & $\begin{array}{l}3.41 \\
(1.19)\end{array}$ & 3 & $\begin{array}{l}1.932 \\
(\neq) *\end{array}$ & $\begin{array}{l}2355 \\
(\neq) *\end{array}$ \\
\hline To expose "unethical" companies in the media & $\begin{array}{l}3.67 \\
(1.36)\end{array}$ & 4 & $\begin{array}{l}3.77 \\
(1.27)\end{array}$ & 4 & $\begin{array}{l}-0.374 \\
(\neq)\end{array}$ & $\begin{array}{l}1949 \\
(\neq)\end{array}$ \\
\hline $\begin{array}{l}\text { To invest directly in companies with an ethical } \\
\text { or environmental profile }\end{array}$ & $\begin{array}{l}\mathbf{4 . 4 8} \\
(0.80)\end{array}$ & $\begin{array}{l}5 \\
{[2 ; 5]}\end{array}$ & $\begin{array}{l}\mathbf{4 . 1 9} \\
(0.92)\end{array}$ & 4 & $\begin{array}{l}1.824 \\
(\neq) *\end{array}$ & $\begin{array}{l}2342 \\
(\neq) *\end{array}$ \\
\hline $\begin{array}{l}\text { To be an active owner in both "ethical" and } \\
\text { "unethical" companies }\end{array}$ & $\begin{array}{l}2.88 \\
(1.45)\end{array}$ & 3 & $\begin{array}{l}3.14 \\
(1.44)\end{array}$ & 3 & $\begin{array}{l}-0.958 \\
(\neq)\end{array}$ & $\begin{array}{l}1521 \\
(\neq)\end{array}$ \\
\hline To donate part of the returns to charity & $\begin{array}{l}2.09 \\
(1.04)\end{array}$ & 2 & $\begin{array}{l}2.26 \\
(1.29)\end{array}$ & 2 & $\begin{array}{l}-0.776 \\
(\neq)\end{array}$ & $\begin{array}{l}1857 \\
(\neq)\end{array}$ \\
\hline
\end{tabular}

Sustainable fund investors (SR) that currently invest in socially responsible funds. Conventional investors that are generally interested (INT) to invest in socially responsible funds

In order to investigate investor group differences (SR and INT) concerning the perceived effectiveness of engagement strategies, the respondents were asked to rate various strategies (first column) on a 5-point Likert scale ( $1=$ 'totally ineffective' $\ldots .5=$ 'very effective')

* Significant at the 0.10 level; ** significant at the 0.05 level; *** significant at the 0.01 level

a If not reported, the range of the scale was used to full capacity: [Min; Max] $=[1 ; 5]$

b Two-sample t-test; direction of alternative hypothesis: $\neq$ "two-sided"

c Two-sample Wilcoxon-test; direction of alternative hypothesis: $\neq$ "two-sided"

Despite the fact that inclusion seems to be the preferred strategy among SR and INT investors (cp. Table 9) most research has been done regarding exclusion, which we turn to in the next section.

\subsubsection{Exclusion (negative screening)}

Following Anand and Cowton (1993), we asked for reasons according to which companies should be excluded from the respondent's investment universe. Additionally, we followed McLachlan and Gardner (2004) and asked our respondents to rate each issue on a 4-point scale from 'yes, would invest in' (1) to 'never invest in' (4) (Table 13). When a ranking is formed according to the mean values of each issue, the three investor groups agree that social issues such as "child 


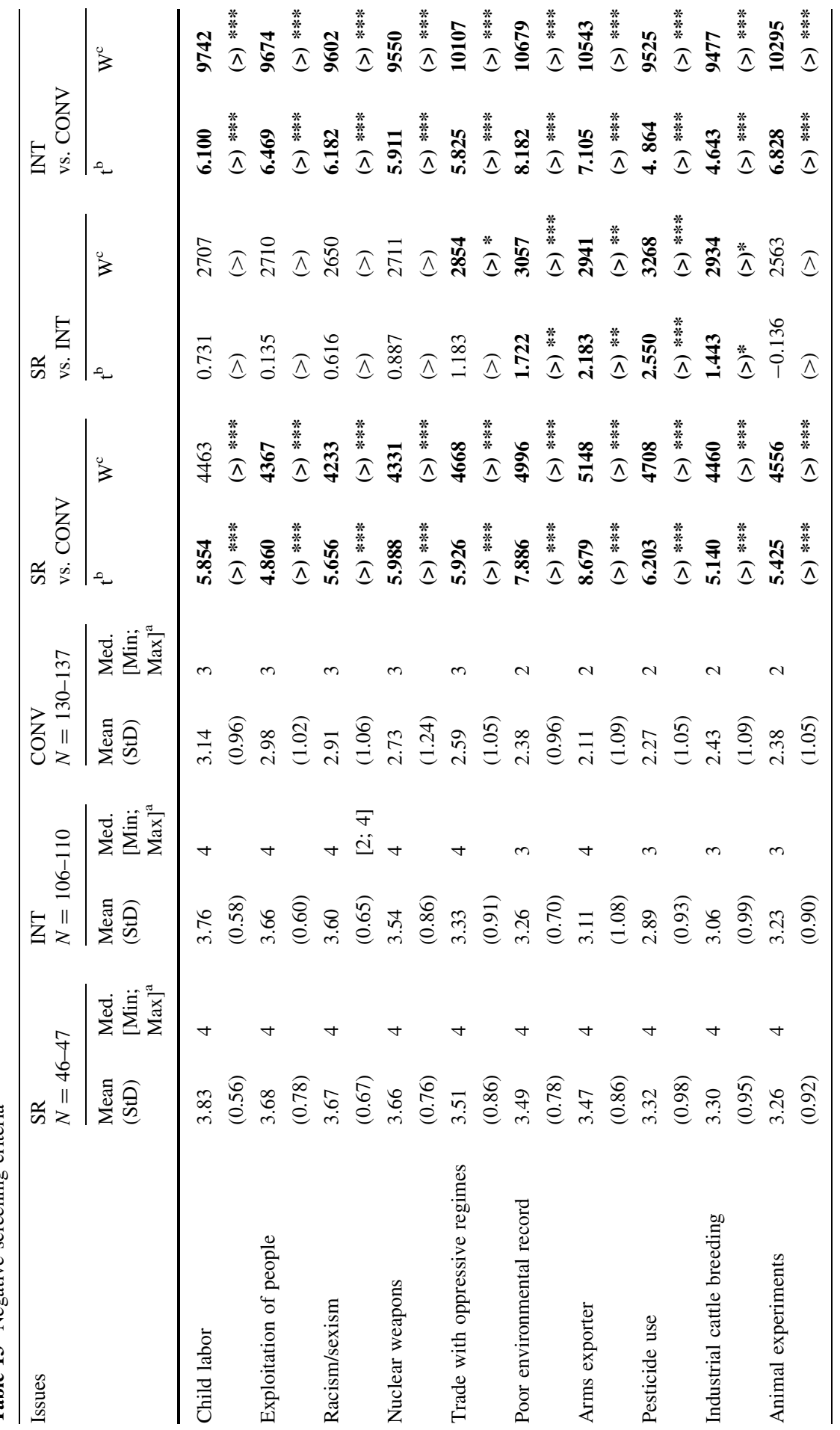




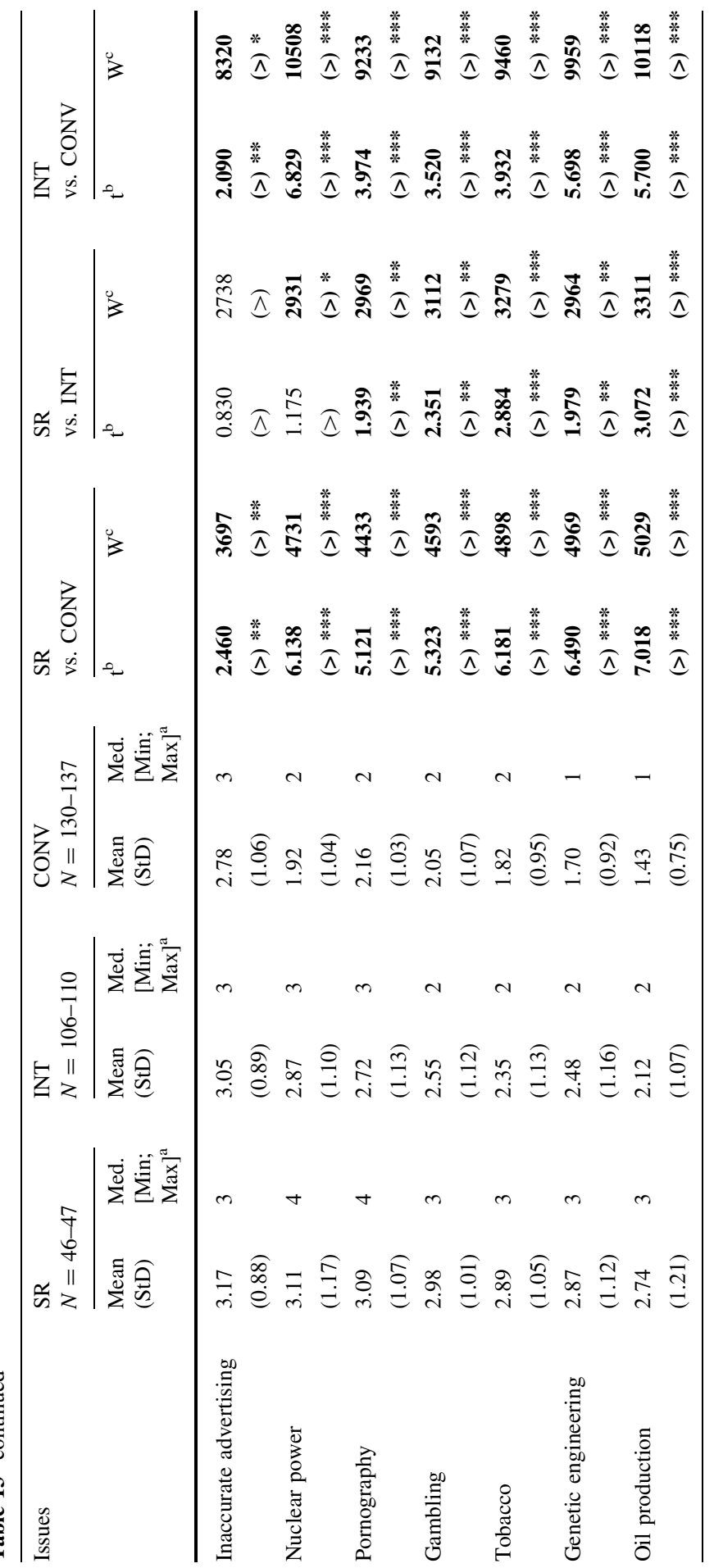




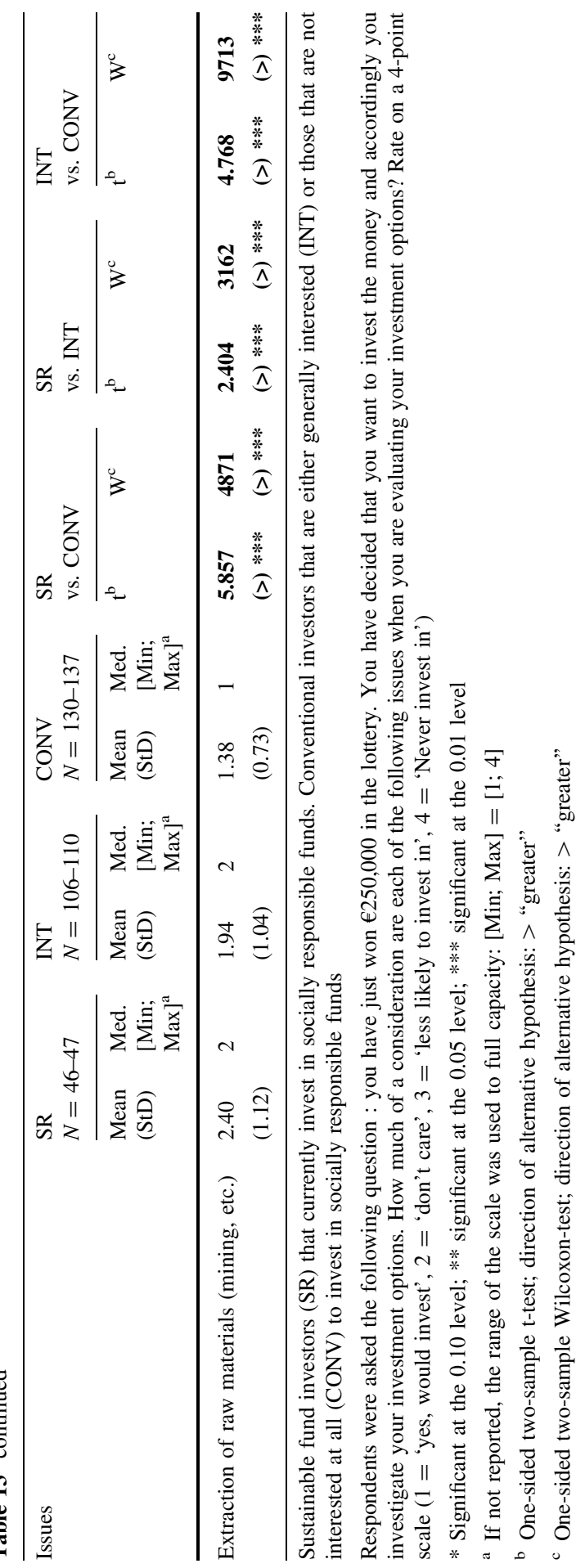


labor' (1), 'exploitation of people' (2), and 'racism or sexism' (3), are the most important when labeling companies as 'not investable'.

In order to test hypothesis H5b, which states that SR and INT investors rate sustainable issues as more important to their investment decisions than CONV investors, we performed one-sided t-tests for each issue, making pairwise comparisons between the three investor groups. Looking at Table 13 it is obvious that hypothesis H5b is confirmed: SR and INT investors rate the presented issues as more important than CONV investors. When it comes to the comparison of SR and INT investors, Table 13 indicates that the picture is less clear but still recognizable since SR fund investors rate the issues as significantly $(\alpha=5 \%)$ more important than INT investors in 9 of 18 cases. This finding again supports the claim that SR fund investors have a more holistic view on sustainability $(\mathrm{H} 3 \mathrm{~b})$, since those nine cases all correspond to moral and ecological issues. Consequently SR and INT investors' views are only equally strong when social issues are concerned.

For the strategies of inclusion and exclusion a decision on how sustainable a company is has to be made. We asked our respondents who, in their opinion, should make this decision. Table 14 shows that SR and INT investors do not trust the fund management with this task, nor do they want a fund's investment universe to be restricted to those of sustainable stock indices. SR fund investors either want to assign an independent advisory committee or an external agency to evaluate stocks'

Table 14 To what extent do you agree to the following statements?

\begin{tabular}{|c|c|c|c|c|c|c|}
\hline \multirow[t]{2}{*}{ Statement } & \multicolumn{2}{|c|}{$\begin{array}{l}\mathrm{SR} \\
N=45-48\end{array}$} & \multicolumn{2}{|c|}{$\begin{array}{l}\text { INT } \\
N=104-110\end{array}$} & \multicolumn{2}{|l|}{$\begin{array}{l}\text { SR } \\
\text { vs. INT }\end{array}$} \\
\hline & $\begin{array}{l}\text { Mean } \\
(\mathrm{StD})\end{array}$ & $\begin{array}{l}\text { Med. } \\
{[\text { Min; }} \\
\quad \text { Max }]^{\mathrm{a}}\end{array}$ & $\begin{array}{l}\text { Mean } \\
(\mathrm{StD})\end{array}$ & $\begin{array}{l}\text { Med. } \\
{[\text { Min; }} \\
\text { Max }]^{\mathrm{a}}\end{array}$ & $t^{b}$ & $\mathrm{~W}^{\mathrm{c}}$ \\
\hline $\begin{array}{l}\text { The fund manager should be supported by } \\
\text { an independent investment advisory } \\
\text { committee when evaluating the } \\
\text { sustainability of stocks }\end{array}$ & $\begin{array}{l}4.36 \\
(0.94)\end{array}$ & 5 & $\begin{array}{l}3.80 \\
(1.05)\end{array}$ & 4 & $\begin{array}{l}3.317 \\
(\neq) * * *\end{array}$ & $\begin{array}{l}3394 \\
(\neq) * * *\end{array}$ \\
\hline $\begin{array}{l}\text { The sustainability rating of stocks should be } \\
\text { carried out by external agencies }\end{array}$ & $\begin{array}{l}4.35 \\
(0.93)\end{array}$ & 5 & $\begin{array}{l}4.01 \\
(1.04)\end{array}$ & 4 & $\begin{array}{l}2.065 \\
(\neq) * *\end{array}$ & $\begin{array}{l}3216 \\
(\neq) * *\end{array}$ \\
\hline $\begin{array}{l}\text { The fund manager should only invest in } \\
\text { stocks that are part of a sustainable } \\
\text { stock index }\end{array}$ & $\begin{array}{l}2.64 \\
(1.33)\end{array}$ & 3 & $\begin{array}{l}2.89 \\
(1.45)\end{array}$ & 3 & $\begin{array}{l}-1.021 \\
(\neq)\end{array}$ & $\begin{array}{l}2111 \\
(\neq)\end{array}$ \\
\hline $\begin{array}{l}\text { The sustainability rating of stocks should be } \\
\text { carried out by the fund's management }\end{array}$ & $\begin{array}{l}2.61 \\
(1.24)\end{array}$ & 3 & $\begin{array}{l}2.66 \\
(1.26)\end{array}$ & 2.5 & $\begin{array}{l}-0.235 \\
(\neq)\end{array}$ & $\begin{array}{l}2395 \\
(\neq)\end{array}$ \\
\hline
\end{tabular}

Sustainable fund investors (SR) that currently invest in socially responsible funds. Conventional investors that are generally interested (INT) to invest in socially responsible funds

SR and INT investors were asked to rate their agreement to several statements on a 5-point Likert scale $(1=$ 'totally disagree' $\ldots 5=$ 'totally agree')

* Significant at the 0.10 level; ** significant at the 0.05 level; *** significant at the 0.01 level

a If not reported, the range of the scale was used to full capacity: [Min; Max $]=[1 ; 5]$

b Two-sample $t$-test; direction of alternative hypothesis: $\neq$ "two-sided"

c Two-sample Wilcoxon-test; direction of alternative hypothesis: $\neq$ "two-sided" 
sustainability. Survey evidence from Haigh (2008) suggests that consumers' reluctance to purchase social funds is associated with consumers' concerns regarding the information integrity of social funds. That is in line with Beal and Goyen (1998) who state that investors greatly depend on the fund managers' judgments regarding the ethical acceptability of investee firms. Consequently, supporting the fund manager with an independent investment advisory committee when evaluating stocks' sustainability might be a suitable way to strengthen the trust towards SR funds. Antonetti and Maklan (2014) state that beliefs of PCE, influenced by pride or guilt, lead to sustainable consumption choices. Thus it is important to strengthen the impression of consumer effectiveness by the 'right' asset selection process of the SR fund, e.g., through selecting the most important negative screening criteria (see Table 13).

\subsubsection{Engagement}

In this section, we take a look at the last undiscussed investment strategy from Table 9: Engagement.

According to Hellsten and Mallin (2006), funds that employ engagement as a part of their investment strategy try to identify areas for improvement in the ethical, social, and environmental policies of the companies they are invested in. Then the funds try to motivate the companies via letters, meetings with top management, etc. to make improvements.

Although engagement is only preferred by few people as their primary investment strategy (Table 9) an overwhelming majority of investors expect their fund to engage: $86.4 \%$ of SR and $80.8 \%$ of INT investors are of the opinion that an ethical fund should influence companies to take stronger social responsibility (Table 15).

Table 15 Return sacrifice for engagement

$\begin{aligned} & \text { Do you think that ethical funds ought to try to make the world a better place, for } \\ & \text { instance by influencing companies to take a stronger social responsibility? If so, to }\end{aligned}$
$\begin{aligned} & \text { [\%] } \\ & N=44\end{aligned}$ $\begin{aligned} & \text { INT } \\ & \text { what extent ought they to be dedicated to this? (choose one) } \\ & N=91\end{aligned}$

Sustainable fund investors (SR) that currently invest in socially responsible funds. Conventional investors that are generally interested (INT) to invest in socially responsible funds

Chi-squared test on respondents' willingness to sacrifice return for engagement among the two investor types: $\chi^{2}=3.348, d f=4, p=0.501$ 
This is in line with the results of Sandberg and Nilsson (2011) and Lewis and Mackenzie (2000b). Concerning the costs of engagement, most SR and INT investors in Germany do not want to sacrifice 'any' or at least 'some' of the funds' return to reach this goal. Only a minority (SR: $13.6 \%$ and INT: $12.1 \%$ ) believe that an ethical fund should dedicate considerable resources or all of its resources to influence companies and therefore should accept much lower returns. This supports the view that investors in Germany mainly see an SR fund as an investment and not as a charitable organization.

Although the majority of both investor groups expect their funds to actively lobby for sustainable improvements in companies, they perceive conducting an active dialogue with 'unethical' companies as only somewhat effective, and being an active owner in both 'ethical' and 'unethical' companies even as somewhat ineffective (Table 12).

The importance of engagement for SR investors and their preferred ways to influence companies are not very well researched. In addition to the above, just fragmented information can be found. The only further evidence on German SR investors is presented by Dorfleitner and Utz (2014) who state that about one-third of their respondents implement their personal moral values through the exertion of voting rights.

\section{Multivariate analysis of investor group differences}

In the following subsections, we seek to identify influential factors on the SR fund investor behavior and significant investor group differences from an objective point of view by using two multivariate methods of analysis: ordinal logistic regression analysis (OLR) and the classification tree (CT) method.

\subsection{Ordinal regression analysis using the logit link function}

One aim of this study is to examine influential factors on the SR fund investors' behavior, i.e., ascending categories of the amount invested in SR funds, which is of an ordinal nature. Therefore, ordinal regression analysis was considered as an appropriate model. As our questionnaire has been conducted in dependence on the existing literature and particularly the three scales (PSA, trust and PCE) developed by Nilsson (2008), especially our variable selection and categorization is closely geared to his analysis in order to be able to make meaningful comparisons between the two studies.

We choose the variable 'amount (\%) of portfolio invested in SR funds' as the dependent variable and categorized it into four groups $(0 \%, 1-20 \%, 21-80 \%$ and 81-100\%). Therefore, the dependent variable was of an ordinal nature. Preparatory investigations indicated that it was not reasonable to comprise the group of INT investors into the estimation. As these investors were frequently not classifiable into the ordered arrangement of the SRI intensity groups (e.g., see Table 2), estimations resulted in very poor or even insignificant model fits. Hence, the first $(0 \%)$ category of the dependent variable comprises the complete group of CONV investors, the 
second category the group of current SR investors with an amount of 1-20\% of their investment portfolio devoted to SR funds, and the third (21-80\%) and fourth (81-100\%) category comprise current SR investors with accordingly stronger SR fund involvements.

In order to comprise a meaningful but still clear and manageable amount of possibly influential factors, the independent variables used in this estimation concern three different categories: attitudinal scale values (PSA, trust, and PCE), demographic characteristics (age, gender, education, income, and place of residence), and subjective perceptions concerning risk and financial performance of SR funds compared to conventional ones. For the sake of clarity, some of the influencing variables were also grouped: perception of return (SR funds' performance is perceived better, similar, or worse), perception of risk (SR funds' risk is perceived lower, similar, or higher), place of residence (middle-size cities or larger cities, countryside or smaller cities: cutoff point 20,000 inhabitants), education (university graduate or not) and income (lower or higher income level: cutoff point $€ 3,600$ monthly household net income).

\subsubsection{Methodical background ${ }^{17}$}

The cumulative link model with the logit link function, also known as the proportional odds model, is specified as:

$$
\log \left(\frac{\gamma_{j}(\boldsymbol{x})}{1-\gamma_{j}(\boldsymbol{x})}\right)=\alpha_{j}-\boldsymbol{\beta}^{\prime} \boldsymbol{x}, \quad j=1, \ldots, J-1
$$

with $\boldsymbol{\beta}$ and $\boldsymbol{x}$ being vectors of dimension $I x 1$ ( $I=$ number of independent metric or dummy variables) and $\gamma_{j}(\boldsymbol{x})$. being the cumulative response probabilities:

$$
\gamma_{j}(\boldsymbol{x})=P(y \leq j \mid \boldsymbol{x}), \quad j=1, \ldots, J-1
$$

( $J=$ number of categories of the ordinal dependent variable). The model assumes that the coefficients $\beta_{i}, i=1, \ldots, I$ do not depend on the level $j$ (proportional odds assumption or assumption of parallel lines). The $\alpha_{j}$ 's satisfy the following constraint since the $\gamma_{j}(\boldsymbol{x})$ increase as a function of $j$ :

$$
\alpha_{1} \leq \alpha_{2} \leq \cdots \leq \alpha_{J-1}
$$

Therefore the estimated coefficients $\hat{\beta}_{i}, i=1, \ldots, I$ indicate whether the probability of belonging to a higher group increases (positive sign) or decreases (negative sign) with increasing values of the independent variable, respectively, the membership to the corresponding category in comparison to the reference category.

\subsubsection{Results of the ordinal logistic regression analysis (OLR)}

Ordinal regression analysis with the logit link function was applied. The results are displayed in Table 16. The essential model assumption of parallel lines was not

$\overline{17}$ For a deeper insight into the technical details, see McCullagh (1980). 
Table 16 Results of the ordinal logistic regression analysis (OLR)

\begin{tabular}{|c|c|c|}
\hline \multicolumn{2}{|l|}{ Variable } & \multirow{2}{*}{$\frac{\text { Estimate }}{10.339 * * *}$} \\
\hline $0 \%$ in SR funds ${ }^{\mathrm{a}}$ & & \\
\hline $1-20 \%$ in SR funds ${ }^{\mathrm{a}}$ & & $12.032 * * *$ \\
\hline $21-80 \%$ in SR funds ${ }^{\mathrm{a}}$ & & $13.493 * * *$ \\
\hline PSA & (metric) & $0.705 * *$ \\
\hline Trust & (metric) & 0.147 \\
\hline PCE & (metric) & $1.773 * * *$ \\
\hline Age & (metric) & -0.011 \\
\hline \multirow[t]{2}{*}{ Gender } & Male (0) & -0.159 \\
\hline & Female (1) & $0^{\mathrm{b}}$ \\
\hline \multirow[t]{2}{*}{ Education } & Not university graduate & -0.990 \\
\hline & University graduate & $0^{\mathrm{b}}$ \\
\hline \multirow[t]{2}{*}{ Income } & Lower income (1) & 0.813 \\
\hline & Higher income (2) & $0^{\mathrm{b}}$ \\
\hline \multirow[t]{2}{*}{ Place of residence } & Middle-size/larger cities (1) & 0.152 \\
\hline & Countryside/smaller cities (2) & $0^{\mathrm{b}}$ \\
\hline \multirow[t]{3}{*}{ Perception of return } & Above average return (1) & 0.808 \\
\hline & Similar return $(2)$ & 0.496 \\
\hline & Below average return (3) & $0^{\mathrm{b}}$ \\
\hline \multirow[t]{3}{*}{ Perception of risk } & Lower risk (1) & 0.957 \\
\hline & Similar risk (2) & 0.207 \\
\hline & Higher risk (3) & $0^{\mathrm{b}}$ \\
\hline \multirow[t]{4}{*}{ Results } & Cox \& Snell $\mathrm{R}^{2}$ & 0.491 \\
\hline & Nagelkerke $\mathrm{R}^{2}$ & 0.583 \\
\hline & McFadden $\mathrm{R}^{2}$ & 0.366 \\
\hline & $\chi^{2}(d f=12 ; N=114)$ & $77.009 * * *$ \\
\hline
\end{tabular}

\footnotetext{
* Significant at the 0.10 level; ** significant at the 0.05 level; *** significant at the 0.01 level

a The dependent variable 'amount (\%) of portfolio invested in SR funds' has been categorized into four groups: CONV investors with no SR investments ('0 \% in SR funds') and current SR fund investors across different investment levels (1-20\%, 21-80\%,81-100\%). The last category operates as reference group

b This parameter is set to zero because it is redundant
}

violated, since the corresponding test result was not significant $(\mathrm{p}=0.998)$. We can therefore assume that the effect of each independent variable on the SR fund investor behavior does not differ among two successive SRI intensity groups.

The model's overall fit was significant $\left(\chi^{2}(d f=12 ; N=114)=77.009\right.$, $\mathrm{p}=0.000$ ), and beyond that, the three different pseudo- $\mathrm{R}^{2}$ measures indicate quite a good overall model fit, implying that a good amount of SR fund investor behavior can be explained.

Two of the three social responsibility constructs showed a significant influence on the SRI behavior: pro-social attitudes (PSA) $(\alpha=5 \%)$ and perceived consumer effectiveness (PCE) $(\alpha=1 \%)$. Both estimates are positive, indicating that investors 
with higher PSA and/or PCE values are more likely to invest greater amounts of their portfolio in SR funds. Although trust in pro-social claims made by SR funds has, as expected, a positive estimate, the impact on SRI behavior is not significant.

Also insignificant are the perceptions of risk and financial return as well as each of the socio-demographic variables. Nonetheless, it should be mentioned that except for the variables income (cp. H1d) and the perception of risk (cp. H4d), the signs of the parameter estimates are consistent with the hypotheses developed in Sect. 2. Summarized, it can be said, that particularly attitudinal properties are influential, whereas the other variables do not significantly affect the intensity of SRI behavior.

According to our set of variables and the model specification, our findings are best comparable to Nilsson's (2008) results. But basically, previous research for other countries using (ordinal) (logit or probit) regression models to estimate the influence of different independent variables on the investors' intensity of SRI involvement or the SRI behavior in general predominantly led to comparable findings: strong dependencies towards attitudinal characteristics, whereas demographic variables seem to be less or rather unimportant (e.g., Williams (2007), Nilsson (2008)). The above supports the assumption that our sample is quite representative regarding SR and CONV investors.

\subsection{Classification tree method}

The OLR is well suited for explaining the determinants of the percentage of the portfolio invested in SR funds for those who already invest in SR funds. But it fails to discover the reasons for INT investors not investing in SR funds though being interested in SEE issues. Therefore, we try using classification (and regression) tree methods to detect essential investor group differences. At first, we looked for a subset of possibly relevant variables resulting in the following choice of 11 variables concerning four different categories: attitudinal scale values (PSA, trust, and PCE, cp. Table 2), different financial statements (subjective perceptions concerning risk (cp. Table 6) and financial performance (cp. Table 5) of SR funds compared to conventional ones, the personal rating of the importance of low risk (cp. Table 8) and high financial return (cp. Table 8) for investments in general, and the expected effect of sustainable actions on a company's stock price (cp. Table 4)) and non-financial criteria (importance of considerations of social, ethical, and environmental (SEE) criteria in the investment process (cp. Table 8)), as well as variables concerning the level of knowledge of the respective respondents (scale value Knowledge as the mean value of all the topics mentioned in Table 17, and sustainable investments solely). This variable selection predominantly results from the comparison of the group-specific mean values, where significant differences between at least two of the three investor groups were observable and additionally under the restriction of covering all possibly relevant topics.

CONV investors already distinguish from SR and INT investors due to their considerably lower attitudinal scale values (cp. Table 2). Especially the significant influence of PSA and PCE toward the SRI behavior is already confirmed by the results of the OLR presented in Sect. 5.1. Additionally, concerning the average rating of the importance of considering SEE criteria in the investment process, a 


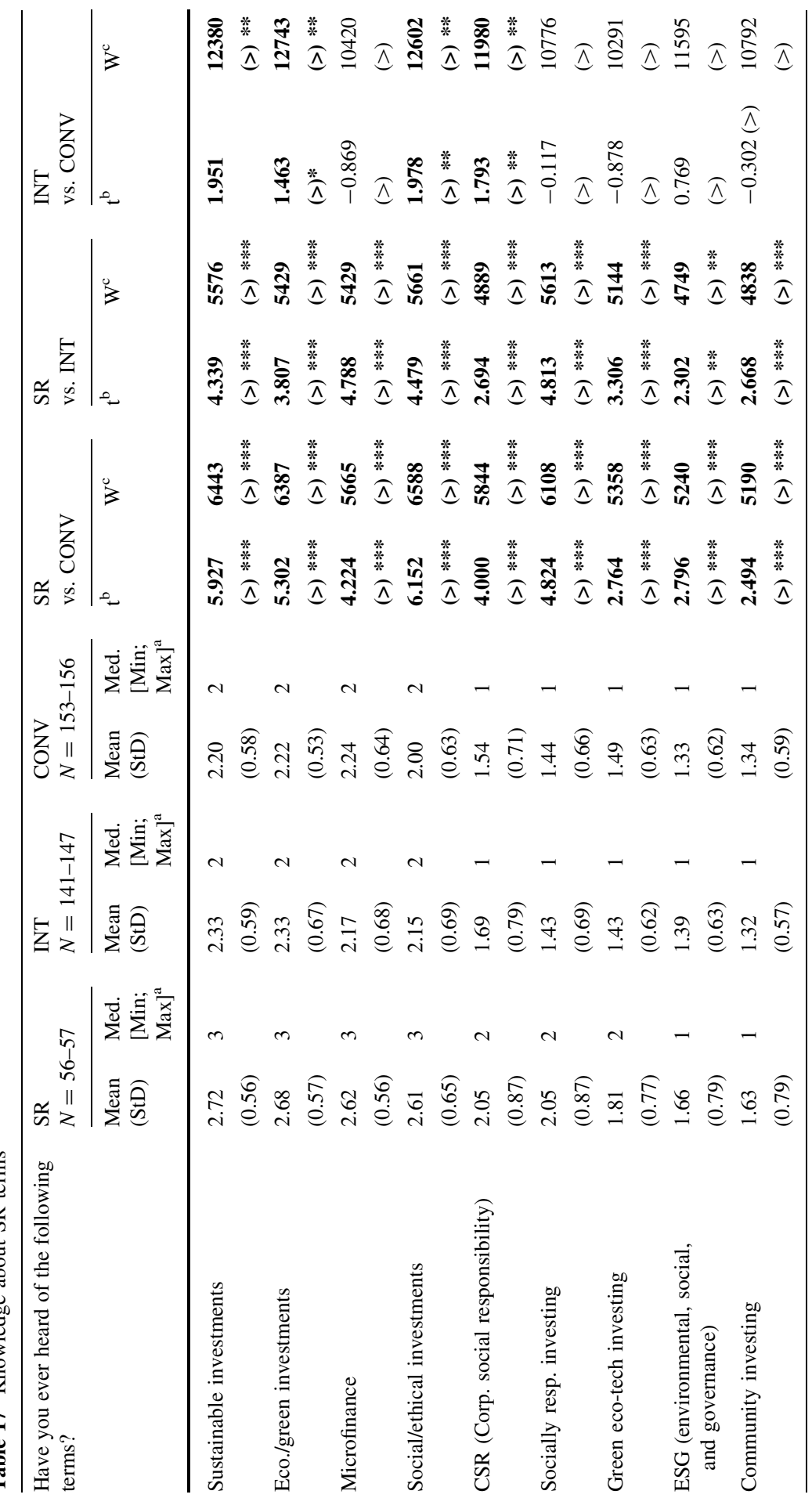




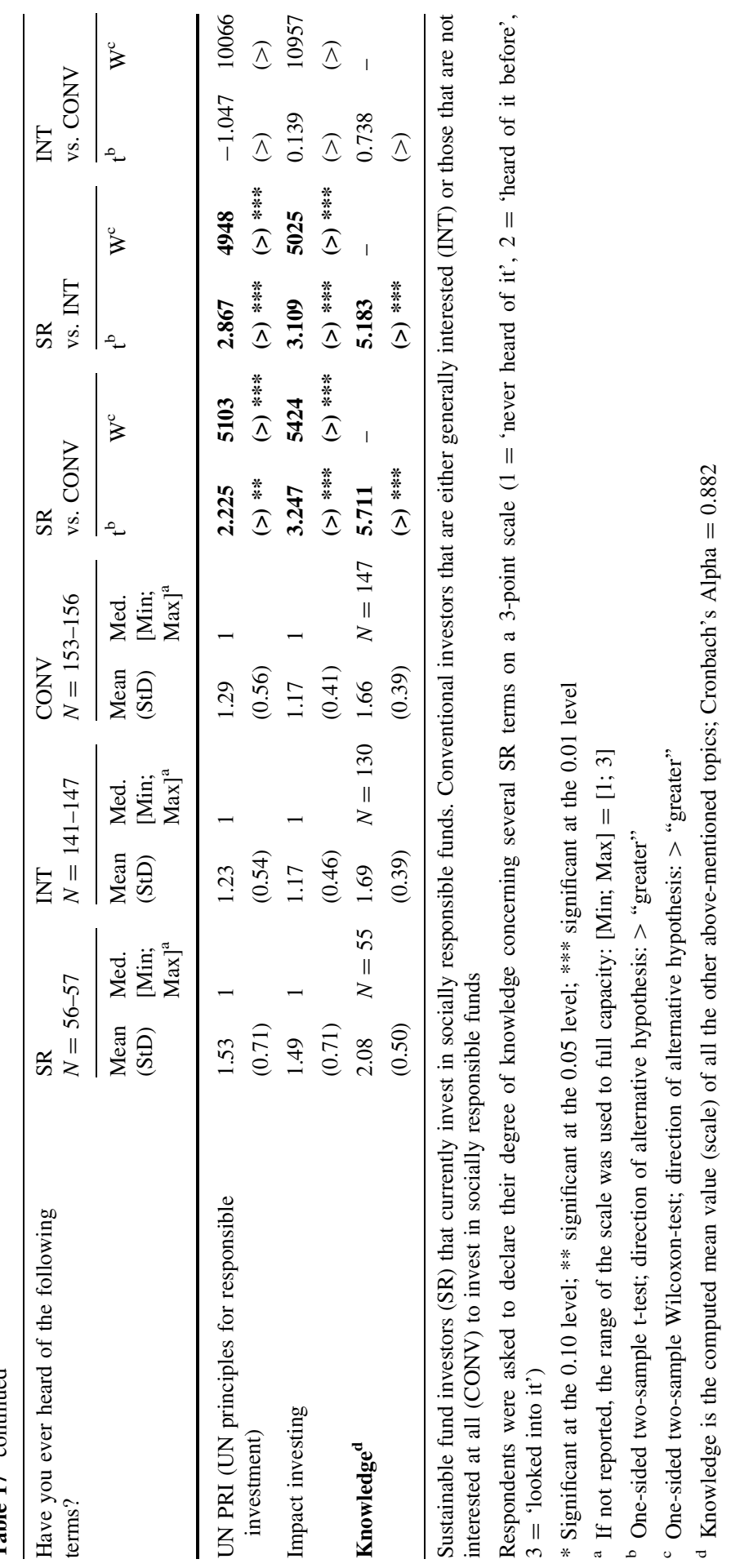


significantly higher rating of SR than INT $(\alpha=1 \%)$ and INT than CONV investors $(\alpha=1 \%)$ could be confirmed in Sect. 4.3 (cp. Table 8). Besides, the $t$-test results of the pairwise comparisons of the mean values concerning the level of knowledge about SR terms of the three investor groups (cp. Table 17) suggest this scale to be useful for further separating INT from SR fund investors since their average knowledge about SR terms differ significantly, with INT investors possessing on average no higher level of knowledge than CONV investors.

\subsubsection{Methodical background ${ }^{18}$}

The most popular algorithm for binary recursive partitioning is based on the work of Breiman et al. (1984). Due to the necessity of cost-complexity pruning and the regular criticism of not being founded on a statistical criterion, Hothorn et al. (2006) readapted the theory to overcome the associated problems of overfitting and biased variable selection. Hence, they present a unified framework for binary recursive partitioning which embeds tree-structured regression models into a well-defined theory of conditional inference procedures. Additionally, stopping criteria based on multiple test procedures are implemented.

The algorithm contains the following three steps:

1. Test the global null hypothesis of independence between any of the covariates $X_{i}(i=1, \ldots, I$ with $I=$ number of independent variables) and the response variable $Y$. Stop if this hypothesis cannot be rejected. Otherwise select the covariate $X_{i^{*}}$ with the strongest association to $Y$ measured by test statistics or $\mathrm{p}$ values indicating the deviation from the partial hypotheses $H_{0}^{i}: D\left(Y \mid X_{i}\right)=$ $D(Y), i=1, \ldots, I$ (i.e., there is no information about the response variable $Y$ covered by covariate $X_{i}$ ).

2. Split the data according to $X_{i^{*}}$ into two disjoint subsets $A^{*}$ and $X_{i^{*}} \backslash A^{*}$. Thereby, the optimal split in covariate $X_{i^{*}}$ exhibits the greatest discrepancy between each possible subset $A$ and $X_{i^{*}} \backslash A$.

3. Recursively repeat step 1 and 2 .

Summarized, the first step defines the variable selection criteria as well as the stopping rule. In the second step the splitting procedure, ${ }^{19}$ with respect to determining the best binary split, is described. Step 3 simply presents the recursive character of the algorithm. Therefore, each node of a tree is represented trough a case weights vector $\boldsymbol{w}=\left(w_{1}, \ldots, w_{n}\right)$ ( $n=$ total number of observations) with $w_{i} \neq 0$ if the respective node contains the corresponding observation, else $w_{i}=0$. Hence, $\boldsymbol{w}$ indicates the relevant data for the next possible split.

The approach by Hothorn et al. (2006) is applicable to regression problems with arbitrary scaled response variables and covariates. Therefore, it is well suited for the classification problem at hand.

\footnotetext{
${ }^{18}$ For a deeper insight into the technical details, see Hothorn et al. (2006).

19 The variable selection criteria as well as the splitting procedure are based on the permutation test framework developed by Strasser and Weber (1999). The stopping rule is based on multiple test procedures.
} 


\subsubsection{Results of the classification tree (CT) method}

A classification tree based on the eleven variables above is created following statistical test criteria and the result is displayed in Fig. 1. Identified relevant variables to separate between the three investor groups are again the two attitudinal scale values PCE and PSA, the investors' rating of the importance of considerations of SEE criteria in their investment process (SEE), as well as the investors' average knowledge about SR terms. All the other variables under consideration do not significantly raise the purity of the separation between SR, INT and CONV investors and are therefore not included in the classification tree in Fig. 1.

The main investor group characteristics resulting from the CT method can be summarized as follows: most CONV investors consider SEE issues as (completely) unimportant for their investment process and state lower PCE values (e.g., cp. Node 2 and 4). On the contrary, SR fund investors predominantly show values for the scales PCE, Knowledge, and PSA in the upper value range (e.g., cp. Node 8 and 9). In comparison to SR fund investors, INT investors particularly stand out due to their lower level of knowledge about SR terms (cp. Node 6), but are hardly distinguishable from SR fund investors when knowledge values are also above average (cp. Node 8). Besides, slightly lower PSA values for INT investors than for SR fund investors might be expected.

These results confirm former test results for investor group differences based on t-tests (Wilcoxon-tests) and/or descriptive values (mean, median) compiled in Sect. 4 for the attitudinal scale values PSA and PCE (see Sect. 4.1) as well as for the importance of considerations of SEE criteria in their investment process (see Sect. 4.3). Besides, the results obtained by the CT method are in line with the literature underlying the hypothesis development in Sect. 2: According to McLachlan and Gardner (2004), SR investors rate SEE issues as more important to their investment decision than conventional investors. Straughan and Roberts (1999) already identified PCE as a strong predictor of ecologically conscious consumer behavior that could be affirmed by Nilsson (2008): He states a significant positive impact of PCE as well as PSA on the investment behavior in SR funds. This could be confirmed by the results of the OLR in Sect. 5.1 and the two scales are again relevant aspects for investor group separation. As to date, literature primarily focused on group differences between SR and conventional investors, we additionally developed the scale Knowledge (cp. Table 17) that significantly separates between SR and INT investors.

Concluding, several variables, that showed significant investor group differences according to t-test (Wilcoxon-test) results (see Sect. 4), were not relevant for investor group separation. Therefore, the CT method identified a small number (four) of relevant variables (eleven) which one could exclusively refer to when being interested in the classification of new, ungrouped investors. This might be relevant for advisory services when trying to identify new SR fund investors.

The goodness-of-fit results of the CT method are noted in Table 18, displaying the cross-tabulation of the observed versus the predicted group membership of the investors. Overall, $65.6 \%$ of the investors could be accurately classified. Compared to the goodness of classification by chance $(46.1 \%$, being the a priori probability 


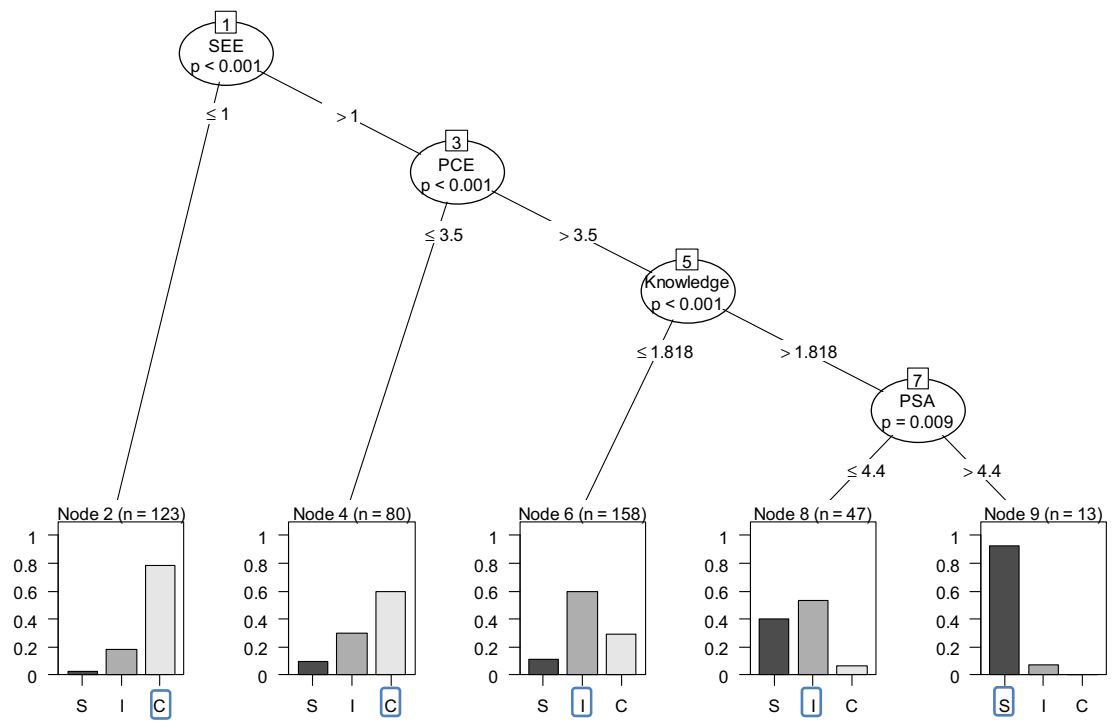

Fig. 1 Classification Tree for SR fund, INT, and CONV investors The classification tree method identifies the following variables being essential factors for investor group differences concerning investment decisions regarding SR funds: PSA pro-social attitudes, $P C E$ perceived consumer effectiveness, $S E E$ subjective rating of the importance of considerations of social, ethical, and environmental criteria in the investment process and Knowledge (mean value of knowledge concerning different SR terms). S: SR fund investors; I: INT investors; C: CONV investors

for the largest investor group, the CONV investors $\left.\left(\mathrm{N}_{\mathrm{CONV}}=194\right)\right)$, the model fit leads to a noticeable improvement, but it is not completely satisfying.

A more detailed investigation of sources for misclassification by regarding the group-specific rates of accuracy particularly points to the SR fund investors, predominantly being predicted as INT investors due to a considerably lower a priori probability (14.3\% compared to $39.7 \%$ ). Therefore, differing a priori probabilities for group membership turn out to be a nontrivial problem of the CT method. The precision of classification, i.e., the probability of once being predicted actually belonging to the predicted group, is lowest for INT investors $(58.0 \%)$ and highest for SR fund investors $(92.3 \%)$. However, CONV investors were predicted with an accuracy rate of $74.7 \%$ and a precision rate of $71.4 \%$.

Altogether, these results emphasize the difficulty to separate between SR and INT investors, whereas CONV investors are quite well distinguishable. A possible modification to improve the goodness of classification might be to take the results of the CT method from Table 18 and to merge the SR and INT investors, representing the group of investors being generally reachable for SR investing (REACH) due to being already active or at least interested in this topic. Despite the obviously remaining heterogeneity within the two resulting investor groups (REACH and CONV), the overall correct classification rate increases to $74.6 \%$ and is quite satisfactory with an accuracy rate of $74.4 \%$ and a precision rate of $77.5 \%$ for the merged group of SR and INT investors (cp. Table 19). 
Table 18 Classification quality of the classification tree method

\begin{tabular}{llccccccc}
\hline & & \multicolumn{3}{l}{ Pred. } & & Total & A priori probability [\%] & Accuracy [\%] \\
\cline { 3 - 5 } & & SR & INT & CONV & & & \\
\hline Obs. & SR & $\mathbf{1 2}$ & 37 & 11 & 60 & 14.3 & $\mathbf{2 0 . 0}$ \\
& INT & 1 & $\mathbf{1 1 9}$ & 47 & 167 & 39.7 & $\mathbf{7 1 . 3}$ \\
& CONV & 0 & 49 & $\mathbf{1 4 5}$ & 194 & 46.1 & $\mathbf{7 4 . 7}$ \\
Total & & 13 & 205 & 203 & $\mathbf{4 2 1}$ & & $\mathbf{6 5 . 6}$ \\
Precision $[\%]$ & & $\mathbf{9 2 . 3}$ & $\mathbf{5 8 . 0}$ & $\mathbf{7 1 . 4}$ & & & \\
\hline
\end{tabular}

Sustainable fund investors (SR) that currently invest in socially responsible funds. Conventional investors that are either generally interested (INT) or those that are not interested at all (CONV) to invest in socially responsible funds

Goodness-of-fit results of the classification tree method are reported, displaying the cross-tabulation of the observed (Obs.) versus the predicted (Pred.) group membership of the investors. The percentage of each investor group that could be accurately classified is shown in column: Accuracy. These values can then be compared to the goodness of classification by chance (column: A priori probability). The precision of classification, i.e., the probability of once being predicted actually belonging to the predicted group, is given in row: Precision

\subsection{Reasons for not investing in SR Funds}

Apart from the above attempt to identify reasons of INT investors for not investing in SR funds though being interested, we asked them to state on a 5-point Likert scale anchored by 'totally disagree' (1) and 'totally agree' (5) their personal level of agreement concerning different possible reasons for not investing in SR funds. Besides, we confronted the CONV investors with identical options for reasons for not being interested in SR funds at all and asked them to state their subjective point of view. The results are displayed in Table 20.

The main reasons for not (yet) investing in SR funds obviously differ. Whereas INT investors widely agree with the statements of being insufficiently informed ('I feel uninformed about SR funds', 'I do not know enough about SR funds') and blame their banks' inactivity ('My bank did not offer SR funds'), CONV investors are predominantly convinced that 'SR funds do not help to solve SEE problems', '[they] do not understand how the principles of SR funds relate to SEE issues', and perceive SR funds' performance to be too bad.

Summarized, INT investors feel insufficiently informed, whereupon their own initiative for changing it is not very pronounced. On the contrary, CONV investors are particularly doubtful about SR funds' effectiveness.

To gain a deeper understanding about the respondents' perceptions of individual knowledge, we took a detailed look at their more objective ${ }^{20}$ level of knowledge about the four most commonly known SR terms ('Sustainable Investments', 'Eco./ Green Investments', 'Microfinance', 'Social/Ethical Investments', cp. Table 17) and compared them to their agreement to the statement "I feel uninformed about SR

\footnotetext{
${ }^{20}$ The respondents knowledge about SR terms was captured on a 3-point scale $(1=$ 'never heard of it', 2 = 'heard of it before', 3 = 'looked into it') that hardly allows individual interpretations.
} 
Table 19 Classification quality of the classification tree method after merging

\begin{tabular}{|c|c|c|c|c|c|}
\hline & & \multicolumn{2}{|l|}{ Pred. } & \multirow[t]{2}{*}{ Total } & \multirow[t]{2}{*}{ Accuracy $[\%]$} \\
\hline & & REACH & $\mathrm{CONV}$ & & \\
\hline \multirow[t]{2}{*}{ Obs. } & REACH & 169 & 58 & 227 & 74.4 \\
\hline & CONV & 49 & 145 & 194 & 74.7 \\
\hline \multicolumn{2}{|l|}{ Total } & 218 & 203 & 421 & \\
\hline \multicolumn{2}{|c|}{ Precision [\%] } & 77.5 & 71.4 & & 74.6 \\
\hline
\end{tabular}

Sustainable fund investors (SR) that currently invest in and conventional investors that are generally interested (INT) to invest in socially responsible funds are merged to an investor group being generally reachable (REACH) for SR fund investing. Conventional investors (CONV) are not interested at all to invest in socially responsible funds

Goodness-of-fit results of the classification tree method after merging SR and INT investors (REACH) are reported, displaying the cross-tabulation of the observed (Obs.) versus the predicted (Pred.) group membership of the investors. The percentage of each group that could be accurately classified is shown in column: Accuracy. The precision of classification, i.e., the probability of once being predicted actually belonging to the predicted group, is given in row: Precision

funds" (cp. Table 20). Hence, for each of the four aforementioned aspects we grouped the INT and CONV investors corresponding to their level of knowledge ( 1 = 'never heard of it', 2 = 'heard of it before', $3=$ 'looked into it'), resulting into three subgroups, respectively. For each of the SR terms the comparison of INT and CONV investors with at least some previous knowledge $(2=$ 'heard of it before', 3 = 'looked into it') each on the same level (2 or 3) leads to the conclusion, that the perception of being insufficiently informed is significantly ( $\alpha=1 \%$ ) more pronounced for the INT than the CONV subgroups. ${ }^{21}$ Concerning the statement "I do not know enough about SR funds" (cp. Table 20) the findings are qualitatively comparable: although the knowledge of the two investor groups is objectively similar, INT investors see their knowledge deficit as a greater hindrance regarding a possible investment in SR funds, when compared to CONV investors.

Concluding, the findings can be summarized as follows:

Firstly, the results of the OLR confirm previous findings that the intensity of SRI behavior particularly depends on attitudinal properties (e.g., PSA, PCE), whereas subjective perceptions concerning risk and financial performance and/or demographic characteristics seem to be less or rather unimportant.

Secondly, the CT method researching investor group differences identified again the two attitudinal scale values PCE and PSA, the investors' rating of the importance of considerations of SEE criteria in their investment process (SEE), as well as the investors' average knowledge about SR terms as relevant variables to separate between the three investor groups: CONV investors consider SEE issues as predominantly unimportant for their investment process and those who rank SEE

\footnotetext{
${ }^{21}$ For each of the four most commonly known SR terms and each level of knowledge, we performed one-sided (alternative hypothesis: "greater") t-test $(\alpha=1 \%)$, comparing the mean value of INT and CONV investors concerning their agreement to the statement "I feel uninformed about SR funds". The corresponding non-parametric Wilcoxon-tests completely support the $t$-test results. Detailed tables are available from the authors upon request.
} 
Table 20 Reasons for not investing/not being interested in SR funds

\begin{tabular}{|c|c|c|c|c|c|c|c|c|}
\hline \multirow[t]{2}{*}{ Statement } & \multicolumn{3}{|c|}{$\begin{array}{l}\text { INT without former } \\
\text { SR investors }\end{array}$} & \multicolumn{3}{|l|}{ CONV } & \multicolumn{2}{|c|}{$\begin{array}{l}\text { INT without } \\
\text { former SR } \\
\text { investors } \\
\text { vs. CONV }\end{array}$} \\
\hline & $\begin{array}{l}\text { Mean } \\
(\mathrm{StD})\end{array}$ & $\begin{array}{l}\text { Med. } \\
{[\text { Min; }} \\
\text { Max }]^{\mathrm{b}}\end{array}$ & $\mathrm{N}$ & $\begin{array}{l}\text { Mean } \\
(\mathrm{StD})\end{array}$ & $\begin{array}{l}\text { Med. } \\
{[\text { Min; }} \\
\text { Max }]^{\mathrm{b}}\end{array}$ & $\mathrm{N}$ & $\mathrm{t}^{\mathrm{c}}$ & $\mathrm{W}^{\mathrm{d}}$ \\
\hline $\begin{array}{l}\text { I feel uninformed about SR } \\
\text { funds }\end{array}$ & $\begin{array}{l}3.91 \\
(1.04)\end{array}$ & 4 & 126 & $\begin{array}{l}2.67 \\
(1.34)\end{array}$ & 3 & 122 & $\begin{array}{l}8.144 \\
(\neq) * * *\end{array}$ & $\begin{array}{l}11613 \\
(\neq) * * *\end{array}$ \\
\hline $\begin{array}{l}\text { My bank did not offer SR } \\
\text { funds }\end{array}$ & $\begin{array}{l}\mathbf{3 . 8 9} \\
(1.51)\end{array}$ & 5 & 98 & $\begin{array}{l}3.16 \\
(1.64)\end{array}$ & 3 & 90 & $\begin{array}{l}3.179 \\
(\neq) * * *\end{array}$ & $\begin{array}{l}\mathbf{5 5 5 7} \\
(\neq) * * *\end{array}$ \\
\hline $\begin{array}{l}\text { I do not know enough about } \\
\text { SR funds }\end{array}$ & $\begin{array}{l}\mathbf{3 . 6 7} \\
(1.20)\end{array}$ & 4 & 125 & $\begin{array}{l}3.00 \\
(1.41)\end{array}$ & 3 & 121 & $\begin{array}{l}4.018 \\
(\neq) * * *\end{array}$ & $\begin{array}{l}9615 \\
(\neq) * * *\end{array}$ \\
\hline $\begin{array}{l}\text { The number of available SR } \\
\text { funds is not sufficient }\end{array}$ & $\begin{array}{l}3.47 \\
(1.03)\end{array}$ & 3 & 99 & $\begin{array}{l}2.44 \\
(1.24)\end{array}$ & 2 & 102 & $\begin{array}{l}6.429 \\
(\neq) * * *\end{array}$ & $\begin{array}{l}7408 \\
(\neq) * * *\end{array}$ \\
\hline $\begin{array}{l}\text { The investment criteria of SR } \\
\text { funds are unclear to me }\end{array}$ & $\begin{array}{l}3.35 \\
(1.27)\end{array}$ & 4 & 109 & $\begin{array}{l}3.25 \\
(1.36)\end{array}$ & 3 & 122 & $\begin{array}{l}0.594 \\
(\neq)\end{array}$ & $\begin{array}{l}6928 \\
(\neq)\end{array}$ \\
\hline SR funds perform too bad & $\begin{array}{l}3.20 \\
(1.19)\end{array}$ & 3 & 104 & $\begin{array}{l}3.57 \\
(1.28)\end{array}$ & 4 & 115 & $\begin{array}{l}-2.175 \\
(\neq) * *\end{array}$ & $\begin{array}{l}4938 \\
(\neq) * *\end{array}$ \\
\hline $\begin{array}{l}\text { I do not have enough liquid } \\
\text { funds }\end{array}$ & $\begin{array}{l}3.03 \\
(1.43)\end{array}$ & 3 & 117 & $\begin{array}{l}2.74 \\
(1.61)\end{array}$ & 3 & 113 & $\begin{array}{l}1.403 \\
(\neq)\end{array}$ & $\begin{array}{l}7275 \\
(\neq)\end{array}$ \\
\hline SR funds are not transparent & $\begin{array}{l}2.99 \\
(1.12)\end{array}$ & 3 & 108 & $\begin{array}{l}3.33 \\
(1.31)\end{array}$ & 4 & 119 & $\begin{array}{l}-\mathbf{2 . 0 8 7} \\
(\neq) * *\end{array}$ & $\begin{array}{l}5317 \\
(\neq) * *\end{array}$ \\
\hline $\begin{array}{l}\text { SR funds do not help to solve } \\
\text { SEE problems }\end{array}$ & $\begin{array}{l}2.74 \\
(1.21)\end{array}$ & 3 & 114 & $\begin{array}{l}4.12 \\
(1.19)\end{array}$ & 5 & 130 & $\begin{array}{l}-8.954 \\
(\neq) * * *\end{array}$ & $\begin{array}{l}3079 \\
(\neq) * * *\end{array}$ \\
\hline $\begin{array}{l}\text { I do not understand how the } \\
\text { principles of SR funds } \\
\text { relate to SEE issues }\end{array}$ & $\begin{array}{l}2.70 \\
(1.21)\end{array}$ & 3 & 115 & $\begin{array}{l}\mathbf{3 . 4 1} \\
(1.32)\end{array}$ & 4 & 123 & $\begin{array}{l}-4.343 \\
(\neq) * * *\end{array}$ & $\begin{array}{l}4904 \\
(\neq) * * *\end{array}$ \\
\hline SR funds are too risky & $\begin{array}{l}2.46 \\
(1.14)\end{array}$ & 2 & 102 & $\begin{array}{l}2.22 \\
(1.23)\end{array}$ & 2 & 109 & $\begin{array}{l}1.471 \\
(\neq)\end{array}$ & $\begin{array}{l}6324 \\
(\neq) *\end{array}$ \\
\hline SR funds are too complicated & $\begin{array}{l}2.31 \\
(1.04)\end{array}$ & 2 & 100 & $\begin{array}{l}2.31 \\
(1.24)\end{array}$ & 2 & 112 & $\begin{array}{l}-0.016 \\
(\neq)\end{array}$ & $\begin{array}{l}5738 \\
(\neq)\end{array}$ \\
\hline
\end{tabular}

Conventional investors that are either generally interested (INT) or those that are not interested at all (CONV) to invest in socially responsible funds

INT and CONV investors were asked to rate their agreement to several statements concerning reasons for not investing/not being interested in SR funds on a 5-point Likert scale $(1=$ 'totally disagree'... $5=$ 'totally agree')

* Significant at the 0.10 level; ** significant at the 0.05 level; *** significant at the 0.01 level

a These questions were not completed by former SR investors

${ }^{b}$ If not reported, the range of the scale was used to full capacity: [Min; Max] $=[1 ; 5]$

c Two-sample t-test; direction of alternative hypothesis: $\neq$ "two-sided"

d Two-sample Wilcoxon-test; direction of alternative hypothesis: $\neq$ "two-sided" 
considerations higher, state lower PCE values, whereas SR fund investors exhibit values in the upper value range for the scales PCE, PSA, and Knowledge. Compared to SR fund investors, INT investors stand out by a lower level of knowledge about SR terms, but are hardly distinguishable from the SR fund investors when Knowledge values are also above average. Besides, slightly lower PSA values for INT investors than for SR fund investors might be expected.

But despite the above trends there is no clear differentiation between the three investor groups feasible: solely two out of three investors could be grouped properly according to its characteristics. Altogether, this supports the assumption that SR, INT, as well as CONV investors are rather heterogeneous than homogeneous groups (e.g., Nilsson (2009), Bauer and Smeets (2011), Cheah et al. (2011), Jansson and Biel (2011), Pérez-Gladish et al. (2012)). Nevertheless, to identify an investor as at least interested in SR investing (combining SR and INT investors to one group) leads to a correct classification rate of $75 \%$.

Thirdly, the findings and conclusions especially those drawn from the CT method are supported by further results: The two main reasons for INT investors for not investing in SR funds though being interested are that they feel insufficiently informed and that their bank did not offer any SR funds (cp. Table 20). Beyond that, INT investors see their knowledge deficit as a greater hindrance regarding a possible investment in SR funds, when compared to CONV investors even if they have the same objective level of knowledge. This perception of being uninformed presumably causes INT investors' prejudices and prevents them from becoming an active SR fund investor. Therefore, an increasing flow of relevant and concentrated information accompanied by a professional guidance through skilled bank or (independent) financial advisors (or comparable individuals) could reduce uncertainness and reservation and might induce more INT investors to actually invest in SR funds. On the contrary, CONV investors state to be particularly doubtful about SR funds' effectiveness which leads to lower PCE values, one of the main aspects for explaining the determinants of the percentage of the portfolio invested in SR funds (cp. OLR) as well as for investor group separation (cp. CT method).

\section{Conclusion}

Our exploratory research has shown that SR fund investors are quite similar to those interested in investing sustainably (INT) and very different from those who only consider investing conventionally (CONV). The following is a condensed recapitulation of our findings (with respect to the respondents of our survey) regarding the characteristics of the three investor groups focusing on SR fund investors. The latter are more likely to be female, married and a parent, when comparing them to INT and CONV investors. Furthermore, sustainable fund investors exhibit on average higher values for the three pro-social constructs (pro-social attitudes (PSA), perceived consumer effectiveness (PCE) and trust in SR funds) than the two other investor groups. The results of the OLR have shown that PSA and PCE have a significantly positive impact on the investment behavior: the percentage invested in 
SR funds of an investor's portfolio rises in accordance with these variables. Thus our results suggest that the findings of Nilsson (2008) for Sweden also hold for Germany. PSA and PCE in addition to 'Knowledge' and the 'importance of SEE issues in the investors' investment process' are the only variables needed to correctly identify an investor who is generally reachable for SR fund investments with a classification accuracy rate of almost $75 \%$. This classification approach extends the SRI survey literature as to date there have only been segmentation approaches regarding those who already invest in SR funds (using the investors' degree of concern regarding profit and social responsibility (e.g., Nilsson (2009)) and approaches differentiating between SR investors and those who currently do not invest sustainably (e.g., Junkus and Berry (2010), Cheah et al. (2011)). Accordingly, our study considers heterogeneity among the latter by discriminating further between what we call INT and CONV investors.

Jansson and Biel (2011) are among the first in the survey literature to use the term "sustainable investment" yet they neither clearly define it nor do they ask their respondents what they subsume underneath the term. We attempt to fill this gap, at least for our German sample, and show that it is important to look at how investors define sustainability and the consequences of sustainable actions from companies since the definitions and beliefs of investors are not homogeneous. When it comes to the definition of sustainability, SR fund investors have the most holistic view: $86.2 \%$ of SR fund investors are of the opinion that sustainability comprises ecological, social, ethical and economic issues, whereas only $66.7 \%$ of the INT investors and $42.1 \%$ of the CONV investors share this view. Surprisingly all three investor groups are (on average) of the opinion that ethical, social as well as ecological actions (at least slightly) positively affect a company's stock price. Yet, $\mathrm{SR}$, INT and CONV investors perceive ethical funds to perform worse compared to conventional funds with CONV investors assuming the most negative return difference. Nevertheless, SR fund investors still invest in SR funds as they are less profit orientated than INT and CONV investors.

Additionally, SR fund investors are not only concerned about financial issues, but also about non-financial characteristics of their investments. Despite these facts it is quite difficult to explain why INT investors do not invest in SR funds since they have very similar values for almost all the variables when compared to SR fund investors' values. In our view, the most probable explanation is that SR fund investors do not only think in a pro-social manner but also act in this fashion, which amongst others becomes evident due to their decision to invest in SR funds. Besides, SR fund investors more often engage in voluntary activities than INT investors do (see Table 1). Moreover, the knowledge about SR terms is significantly higher among SR than among INT investors (see Table 17). The fact that SR fund investors are better informed can be interpreted in the way that they actively acquire information, whereas INT investors might be more passive since they state that they feel uninformed about SR funds and criticize that the bank did not offer SR funds (see Table 20). Therefore, SR fund investors seem to be more likely to act on their views with respect to SRI and preferably 'put their money where their mouth is' (Beal and Goyen (1998)). 
According to our survey, the greatest obstacle for further growth of SR funds seems to be the perception that SR funds perform worse than conventional funds. Apart from this, INT investors feel insufficiently informed, whereupon their own initiative for changing this is not very pronounced. On the contrary, CONV investors are particularly doubtful about SR funds' effectiveness. The latter is a good point and an interesting area for further research.

Open Access This article is distributed under the terms of the Creative Commons Attribution 4.0 International License (http://creativecommons.org/licenses/by/4.0/), which permits unrestricted use, distribution, and reproduction in any medium, provided you give appropriate credit to the original author(s) and the source, provide a link to the Creative Commons license, and indicate if changes were made.

\section{Appendix: Pro-social influence [adapted from Nilsson (2008)]}

Background information for questionnaire participant: during their lifetime most people in today's society make many purchases. You make purchasing decisions about everything from large items (i.e., trips, cars, houses) to small everyday items (i.e., groceries).

When you make these purchasing decisions, how important is it for you that the companies you buy from: [5-point Likert scale anchored by very important (5) and not at all important (1)].

Pro-social attitudes (PSA) towards issues relevant to SRI

1. Respect workplace rights (i.e., possibility to freely join trade unions).

2. Work actively with environmental issues (i.e., by reducing environmental effect of products and production).

3. Respect human rights (work against discrimination based on race, gender, or religion).

4. Do not produce goods that could harm people (i.e., weapons).

5. Do not use unethical business practices (i.e., bribery and corruption).

PCE of SRI [5-point Likert scale anchored by totally agree (5) and totally disagree (1)].

1. By investing in SRI every investor can have a positive effect on the environment.

2. Every person has power to influence social problems by investing in responsible companies.

3. It does not matter if I invest my money in SRI mutual funds since one person acting alone cannot make a difference (reversed).

4. It is useless for the individual consumer to do anything about pollution (reversed).

Trust in SRI [5-point Likert scale anchored by totally agree (5) and totally disagree (1)]. 
1. I trust that SRI providers follow the socially responsible guidelines used in their marketing.

2. The SRI funds offered by SRI providers are an honest attempt to improve social issues such as pollution.

3. I trust providers of SRI mutual funds to do their best in trying to get companies to act in a way that reduces social problems such as pollution and third world poverty.

4. I trust that providers of SRI-profiled mutual funds do not invest their capital in companies that manufacture weapons and tobacco.

5. Providers of SRI-profiled mutual funds have no genuine interest in improving the environment since they, like every other company, primarily want to make a profit (reversed).

\section{References}

Anand, P., and C.J. Cowton. 1993. The ethical investor: Exploring dimensions of investment behaviour. Journal of Economic Psychology 14(2): 377-385.

Antonetti, P., and S. Maklan. 2014. Feelings that make a difference: How guilt and pride convince consumers of the effectiveness of sustainable consumption choices. Journal of Business Ethics 124(1): 117-134.

Bardsley, N. 2005. Experimental economics and the artificiality of alteration. Journal of Economic Methodology 12(2): 239-251.

Bauer, R., K. Koedijk, and R. Otten. 2005. International evidence on ethical mutual fund performance and investment style. Journal of Banking \& Finance 29(7): 1751-1767.

Bauer, R., \& Smeets, P. (2011). Some men invest like women: the influence of social values on investment decisions and investor loyalty. SSRN Electronic Journal. doi:10.2139/ssrn.1777085.

Bauer, R., \& Smeets, P. (2015). Social identification and investment decisions. Journal of Economic Behavior and Organization 117: 121-134.

Beal, D., and M. Goyen. 1998. 'Putting your money where your mouth is' a profile of ethical investors. Financial Services Review 7(2): 129-143.

Beal, D.J., M. Goyen, and P. Phillips. 2005. Why do we invest ethically? Journal of Investing 14(3): 66-78.

Blaikie, N.W.H. 2003. Analyzing quantitative data: From description to explanation. London, Thousand Oaks, CA: Sage Publications.

Boulstridge, E., and M. Carrigan. 2000. Do consumers really care about corporate responsibility? Highlighting the attitude-behaviour gap. Journal of Communication Management 4(4): 355-368.

Breiman, L., Friedman, J., Stone, C., \& Olshen, R. (1984). Classification and regression trees. New York [etc.]: Chapman \& Hall; ITP International Thomson Publishing.

Brooker, G. 1976. The self-actualizing socially conscious consumer. Journal of Consumer Research 3(2): 107-112.

Capelle-Blancard, G., and S. Monjon. 2012. Trends in the literature on socially responsible investment: looking for the keys under the lamppost. Business Ethics: A European Review 21(3): 239-250.

Cheah, E.-T., D. Jamali, J.E. Johnson, and M.-C. Sung. 2011. Drivers of corporate social responsibility attitudes: The demography of socially responsible investors. British Journal of Management 22(2): 305-323.

Chegut, A., H. Schenk, and B. Scholtens. 2011. Assessing SRI fund performance research: Best practices in empirical analysis. Sustainable Development 19(2): 77-94.

Chung, J., and G. Monroe. 2003. Exploring social desirability bias. Journal of Business Ethics 44(4): 291-302.

Cortez, M.C., F. Silva, and N. Areal. 2009. The performance of European socially responsible funds. Journal of Business Ethics 87(4): 573-588. 
Cortez, M.C., F. Silva, and N. Areal. 2012. Socially responsible investing in the global market: The performance of US and European funds. International Journal of Finance \& Economics 17(3): 254-271.

Crane, A. 2000. Facing the backlash: Green marketing and strategic reorientation in the 1990s. Journal of Strategic Marketing 8(3): 277-296.

Cullis, J.G., A. Lewis, and A. Winnett. 1992. Paying to be good? U.K. ethical investments. Kyklos 45(1): 3-23.

DAI. 2014a. Aktionärszahlen des deutschen Aktieninstituts 2013. Retrieved June 27, 2014 from https:// www.dai.de/en/what-we-offer/studies-and-statistics/studies.html. Accessed 27 June 2014.

DAI. 2014b. Geschlechtsstruktur der Aktionäre und Besitzer von Aktienfonds und gemischten Fonds.

Deutsche Bundesbank. 2013. Vermögen und Finanzen privater Haushalte in Deutschland: Ergebnisse der Bundesbankstudie.

Diamantopoulos, A., B.B. Schlegelmilch, R.R. Sinkovics, and G.M. Bohlen. 2003. Can sociodemographics still play a role in profiling green consumers? A review of the evidence and an empirical investigation. Journal of Business Research 56(6): 465-480.

Dorfleitner, G., and S. Utz. 2014. Profiling German-speaking socially responsible investors. Qualitative Research in Financial Markets 6(2): 118-156.

FNG. 2014. Marktbericht Nachhaltige Geldanlagen 2013: Deutschland, Österreich und die Schweiz. Retrieved 27 June 2014 from http://www.forum-ng.org/de/nachhaltige-geldanlagen/marktuebersicht. html.

Forum for Sustainable and Responsible Investment. 2013. Report on Sustainable Responsible Investment Trends in the United States 2012. Retrieved Jun 27, 2014 from http://www.ussif.org/trends.

Glac, K. 2009. Understanding socially responsible investing: The effect of decision frames and trade-off options. Journal of Business Ethics 87(S1): 41-55.

Grunert, S. 1993. Everybody seems concerned about the environment: But is this concern reflected in (Danish) consumers' food choice? In European advances in consumer research, ed. G.J. Bamossy, and W.Fred van Raaij, 428-433. Provo, Utah: Association for Consumer Research.

Haigh, M. 2008. What counts in social managed investments: Evidence from an International Survey. Advances in Public Interest Accounting 13: 35-62.

Haigh, M., and J. Hazelton. 2004. Financial markets: A tool for social responsibility? Journal of Business Ethics 52(1): 59-71.

Hellsten, S., and C. Mallin. 2006. Are 'ethical' or 'socially responsible' investments socially responsible? Journal of Business Ethics 66(4): 393-406.

Hothorn, T., K. Hornik, and A. Zeileis. 2006. Unbiased recursive partitioning: A conditional inference framework. Journal of Computational and Graphical Statistics 15(3): 651-674.

Jansson, M., and A. Biel. 2011. Motives to engage in sustainable investment: A comparison between institutional and private investors. Sustainable Development 19(2): 135-142.

Junkus, J.C., and T.C. Berry. 2010. The demographic profile of socially responsible investors. Managerial Finance 36(6): 474-481.

Kempf, A., and P. Osthoff. 2008. SRI funds: Nomen est Omen. Journal of Business Finance \& Accounting 35(9-10): 1276-1294.

Kitzmueller, M., and J. Shimshack. 2012. Economic perspectives on corporate social responsibility. Journal of Economic Literature 50(1): 51-84.

Kreander, N., R. Gray, D. Power, and D. Sinclair. 2002. The financial performance of European ethical funds 1996-1998. Journal of Accounting and Finance 1: 3-22.

Kreander, N., R.H. Gray, D.M. Power, and C.D. Sinclair. 2005. Evaluating the performance of ethical and non-ethical funds: A matched pair analysis. Journal of Business Finance and Accounting 32(7-8): 1465-1493.

Lewis, A., and C. Mackenzie. 2000a. Morals, money, ethical investing and economic psychology. Human Relations 53(2): 179-191.

Lewis, A., and C. Mackenzie. 2000b. Support for investor activism among U.K. ethical investors. Journal of Business Ethics 24(3): 215-222.

McCullagh, P. 1980. Regression models for ordinal data. Journal of the Royal Statistical Society: Series B (Methodological) 42(2): 109-142.

McLachlan, J., and J. Gardner. 2004. A comparison of socially responsible and conventional investors. Journal of Business Ethics 52(1): 11-25.

Michelson, G., N. Wailes, Sandra Van Der Laan, and G. Frost. 2004. Ethical investment processes and outcomes. Journal of Business Ethics 52(1): 1-10. 
Nilsson, J. 2008. Investment with a conscience: Examining the impact of pro-social attitudes and perceived financial performance on socially responsible investment behavior. Journal of Business Ethics 83(2): 307-325.

Nilsson, J. 2009. Segmenting socially responsible mutual fund investors: The influence of financial return and social responsibility. The International Journal of Bank Marketing 27(1): 5-31.

Norman, G. 2010. Likert scales, levels of measurement and the "laws" of statistics. Advances in Health Sciences Education 15(5): 625-632.

Pérez-Gladish, B., K. Benson, and R. Faff. 2012. Profiling socially responsible investors: Australian evidence. Australian Journal of Management 37(2): 189.

Rathner, S. 2013. The influence of primary study characteristics on the performance differential between socially responsible and conventional investment funds: A meta-analysis. Journal of Business Ethics 118(2): 349-363.

Renneboog, L., J. Ter Horst, and C. Zhang. 2008. The price of ethics and stakeholder governance: The performance of socially responsible mutual funds. Special Issue: Contractual Corporate Governance European Corporate Governance Institute (ECGI) Symposium on Contractual Corporate Governance 14(3): 302-322.

Rosen, B.N., D.M. Sandler, and D. Shani. 1991. Social issues and socially responsible investment behavior: A preliminary empirical investigation. Journal of Consumer Affairs 25(2): 221-234.

Sandberg, J., \& J. Nilsson (2011). Conflicting intuitions about ethical investment: A survey among Individual investors. Sustainable Investment and Corporate Governance Working Papers, Sustainable Investment Research Platform, SIRP WP 10-16.

Schröder, M. 2004. The performance of socially responsible investments: Investment funds and indices. Financial Markets and Portfolio Management 18(2): 122-142.

Schueth, S. 2003. Socially responsible investing in the United States. Journal of Business Ethics 43(3): 189-194.

Sparkes, R., and C.J. Cowton. 2004. The maturing of socially responsible investment: A review of the developing link with corporate social responsibility. Journal of Business Ethics 52(1): 45-57.

Statman, M. 2005. Normal investors, then and now. Financial Analysts Journal 61(2): 31-37.

Strasser, H., and C. Weber. 1999. On the asymptotic theory of permutation statistics. Mathematical Methods of Statistics 8: 220-250.

Straughan, R.D., and J.A. Roberts. 1999. Environmental segmentation alternatives: A look at green consumer behavior in the new millennium. Journal of Consumer Marketing 16(6): 558-575.

Tippet, J., and P. Leung. 2001. Defining ethical investment and its demography in Australia. Australian Accounting Review 11(25): 44-55.

Vigeo Rating. 2013. Green, Social and Ethical Funds in Europe: 2013 Review. Retrieved 27 June 2014 from http://www.vigeo.com/csr-rating-agency/en/les-fonds-verts-sociaux-et-ethiques-en-europe.

von Wallis, M., and C. Klein (2015). Ethical requirements and financial interest: A review of the socially responsible investment literature. Business Research 8: 61-98. doi:10.1007/s40685-014-0015-7.

Vyvyan, V., C. Ng, and M. Brimble. 2007. Socially responsible investing: the green attitudes and grey choices of Australian Investors. Corporate Governance: An International Review 15(2): 370-381.

Webley, P., A. Lewis, and C. Mackenzie. 2001. Commitment among ethical investors: An experimental approach. Journal of Economic Psychology 22(1): 27-42.

Williams, G. 2007. Some determinants of the socially responsible investment decision: A cross-country study. Journal of Behavioral Finance 8(1): 43-57.

Wins, A., and B. Zwergel (2015). Private ethical fund investors across countries and time: A survey-based review. Qualitative Research in Financial Markets 7(4): 379-411. 